Data Report on Material Ablation and Shock Pressure Measurements at ZBL

E.Smith, B.Bonahoom, C.De La Cruz

January 16, 2007 
This document was prepared as an account of work sponsored by an agency of the United States Government. Neither the United States Government nor the University of California nor any of their employees, makes any warranty, express or implied, or assumes any legal liability or responsibility for the accuracy, completeness, or usefulness of any information, apparatus, product, or process disclosed, or represents that its use would not infringe privately owned rights. Reference herein to any specific commercial product, process, or service by trade name, trademark, manufacturer, or otherwise, does not necessarily constitute or imply its endorsement, recommendation, or favoring by the United States Government or the University of California. The views and opinions of authors expressed herein do not necessarily state or reflect those of the United States Government or the University of California, and shall not be used for advertising or product endorsement purposes.

This work was performed under the auspices of the U.S. Department of Energy by University of California, Lawrence Livermore National Laboratory under Contract W-7405-Eng-48. 


\title{
Data Report on Material Ablation and Shock Pressure Measurements at ZBL
}

December 2006

\author{
Prepared by \\ Eric Smith \\ Bill Bonahoom \\ Chris De La Cruz \\ Prepared for \\ Lawrence Livermore National Laboratory \\ 4000 Avenue East, L-443 \\ Livermore, CA 94550 \\ Contract No. B5555290 \\ K213
}




\section{Table of Contents}

Section

Page

Executive Summary.....

iv

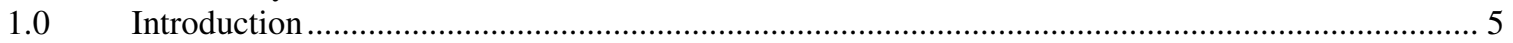

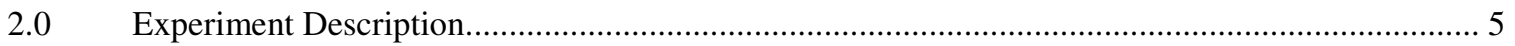

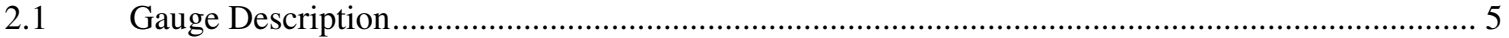

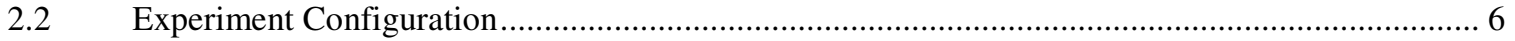

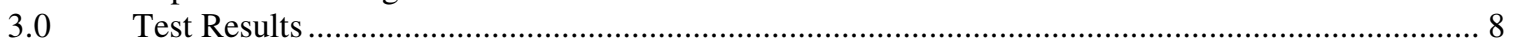

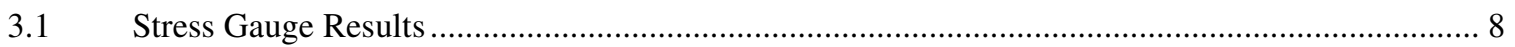

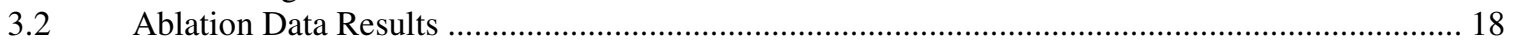

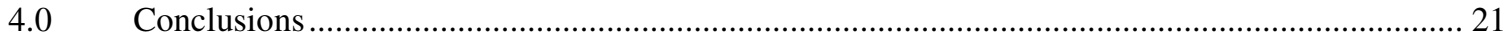

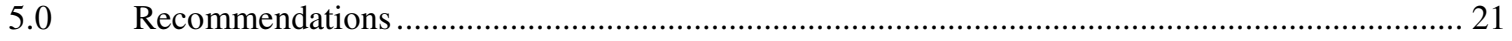

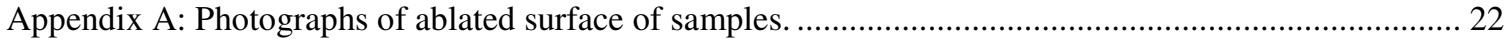

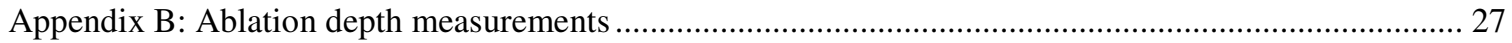

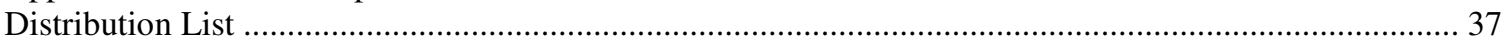




\section{Table of Figures}

Figure $\quad \underline{\text { Page }}$

Figure 1. Quartz and PVDF Pressure Gauge with Sample .................................................. 6

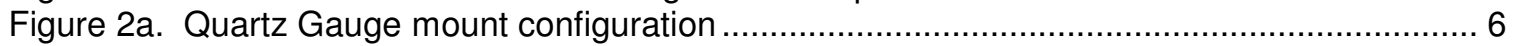

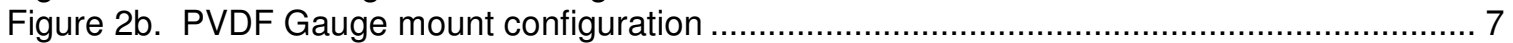

Figure 3. Target assembly to ZBL Chamber mounting hardware ............................................... 7

Figure 4. Target mounted in ZBL test chamber.................................................................... 8

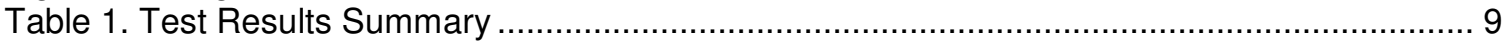

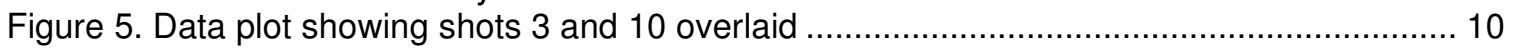

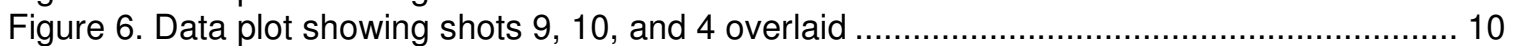

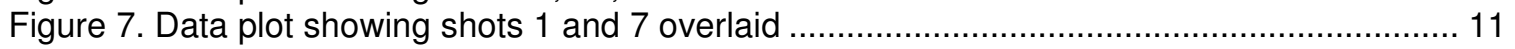

Figure 8. Data plot showing shots 2 and 6 overlaid .......................................................... 11

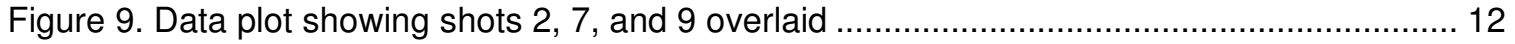

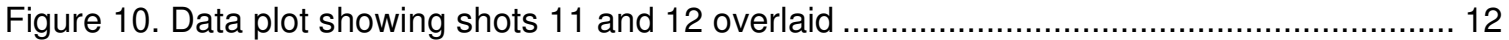

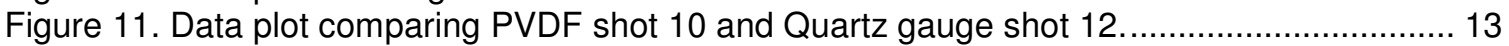

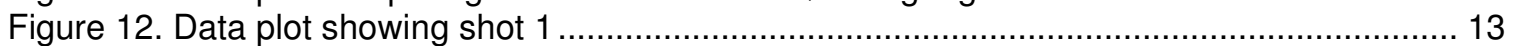

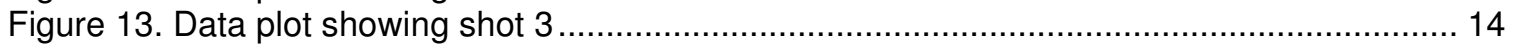

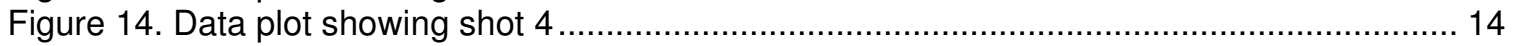

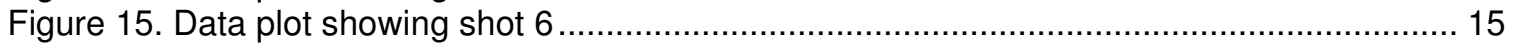

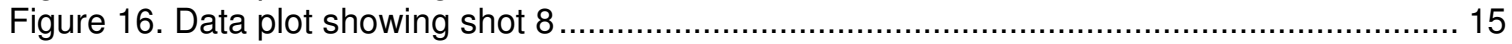

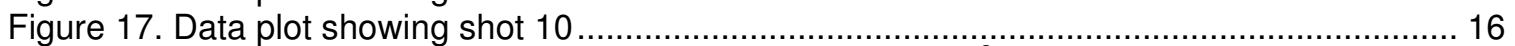

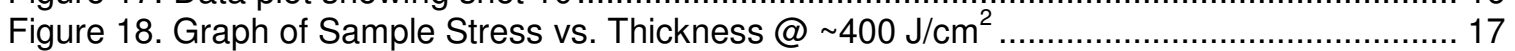

Figure 19. Ablated surface from Shot 12 shows multiple beam depositions ............................... 18

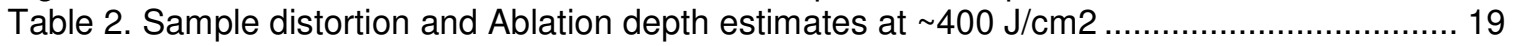

Figure 20. Surface profiles show ablation depth and thermal distortion ................................... 20

for four shots $(4,10,11$, and 12) at nominally $411 \mathrm{~J} / \mathrm{cm} 2$. Profiles were taken left to right relative

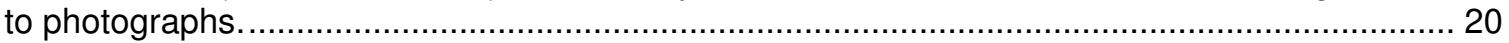

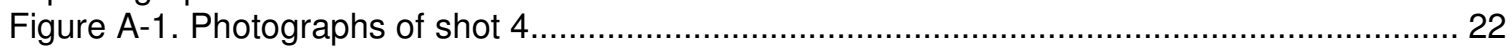

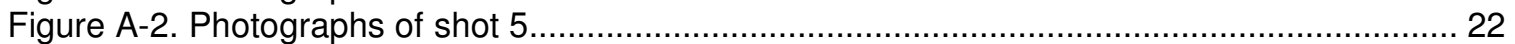

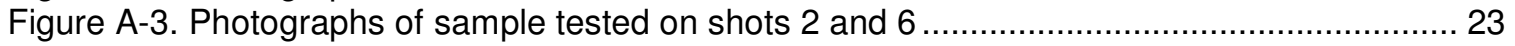

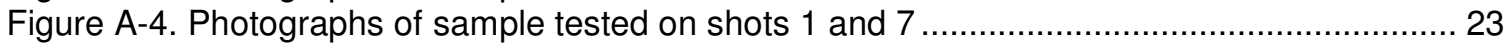

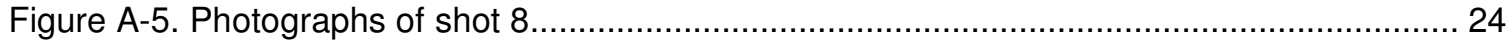

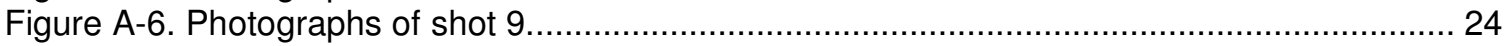

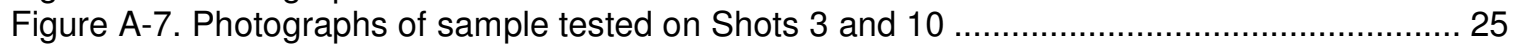

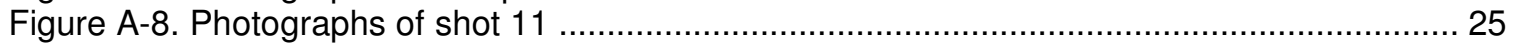

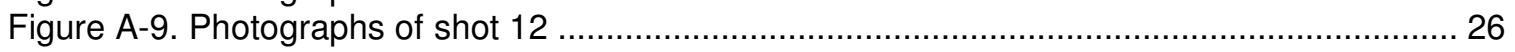

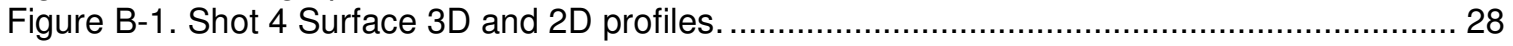

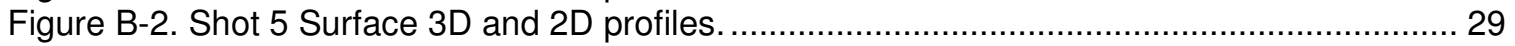

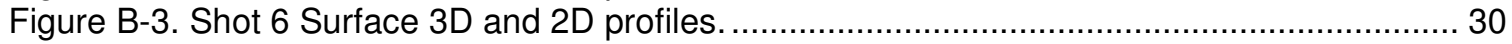

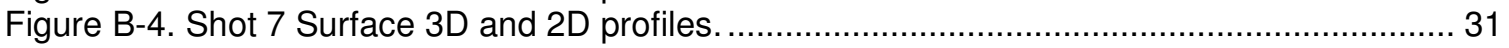

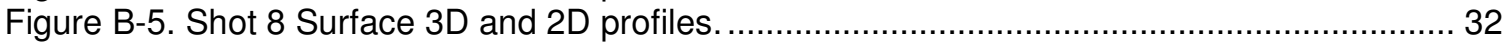

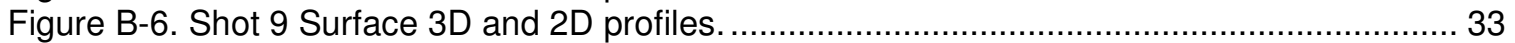

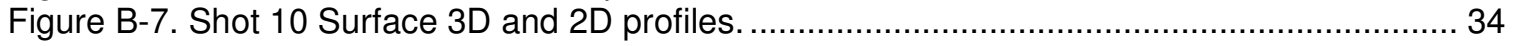

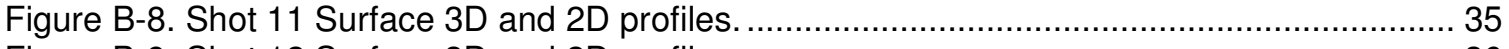

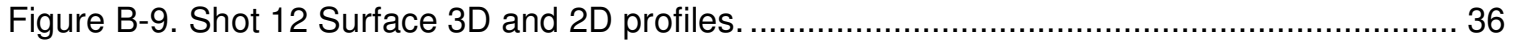


Preface

This work was conducted under the direction of LLNL Primary Investigators Mike Tobin and Kevin Fournier.

Ketch's primary role and mission was to collect stress data. After the test, surface profile data scans were performed by SNL at the request of LLNL. The data files were subsequently made available for data analysis at which time Ktech was tasked with coordination, extraction, analysis and documentation of the data.

\section{Acknowledgments}

The authors wish to acknowledge the contributions of Kelly Seals and Jim Webb for hardware design, fabrication, and fielding and of Mark Krubsack and Eddie Cordero for gauge fabrication. 


\section{Executive Summary}

A series of tests were conducted on ZBL to provide data that can be used to determine the laser coupling coefficient and validate code capabilities. The gauges and cables in the chamber were shielded with conduit and resulted in high fidelity signals.

The stress measurements show a clear trend of peak stress attenuation with propagation distance, as would be expected. The aluminum sample stresses measured were in the 4 to $8 \mathrm{Kbar}$ range. This constitutes a good data set for model validation.

VISAR was considered as a diagnostic for this test series but predicted stress levels were uncertain and we had had good success previously with PVDF at this test facility; plus, the aggressive test schedule and limited number of shots left little opportunity to set up this diagnostic. Shock profile measurements were made with both PVDF and Quartz gauges. The PVDF gauge and the Quartz gauge measured very similar shock pulses transmitted through $1.5-\mathrm{mm}$ thick 2024-T3 samples at a nominal fluence of $400 \mathrm{~J} / \mathrm{cm} 2$. The similarity in the two profiles indicates good correlation between measurement techniques and the differences between the sensor areas allow one to evaluate different parts of the beam.

The laser beam ablated the front surfaces of the samples. Surface profile measurements of the ablated surface were used to estimate the depth of material removed. Ablated sample surface and crater formation indicate a non-uniform hot spot in the center of the sample. 


\subsection{Introduction}

This report describes the laser induced sample stress measurements taken by Ktech on a series of Laser Lethality Experiments conducted by LLNL at the SNL Z-Beamlet Laser (ZBL) Facility. The $1.5 \mathrm{~kJ}$ laser beam was directed to target samples. Pressure gauges were mounted on the backside of the sample and were used to measure the transmitted stress wave profile. LLNL fielded a laser fence to characterize ablated material blow-off at the front surface of the samples. The tests were conducted in November 2005.

Ktech was tasked with pressure gauge fabrication, pressure gauge and laser mirror mounting hardware design and fabrication, data acquisition, and data reduction. Gauge mounting configuration design was coordinated with LLNL. LLNL personnel scheduled the test facility.

\subsection{Experiment Description}

\subsection{Gauge Description}

Ktech PVDF shock pressure gauges were used to measure the transmitted stress wave profiles. These gauges have a high dynamic range, from fractions of a bar to over 100 kbars. This capability was a primary reason the PVDF gauge was selected. The charge output generated by the sensor was measured with a current viewing resistor to measure stress rate. Stress-rate (or current mode) configuration is used in noisy environments to produce high amplitude signals from fast rise time shock pressure pulses.

The basic gauge is shown in Figure 1 with the sample mounted over the sensor. The PVDF sensor is a thin film, $25 \mu \mathrm{m}$-thick, piezoelectric polymer with a 3 x $3 \mathrm{~mm}(0.09 \mathrm{sq}$ $\mathrm{cm}$ ) sensing area. (A $50 \mu \mathrm{m}$-thick film of Teflon insulation covers the impact side of the sensor on one of the targets.) This sensor is backed by Kel-F plastic and placed in an aluminum gauge can (body and cover sleeve) to produce a convenient-to-use gauge package. The gauges were also QA function tested at low pressure prior to use to ensure integrity. 

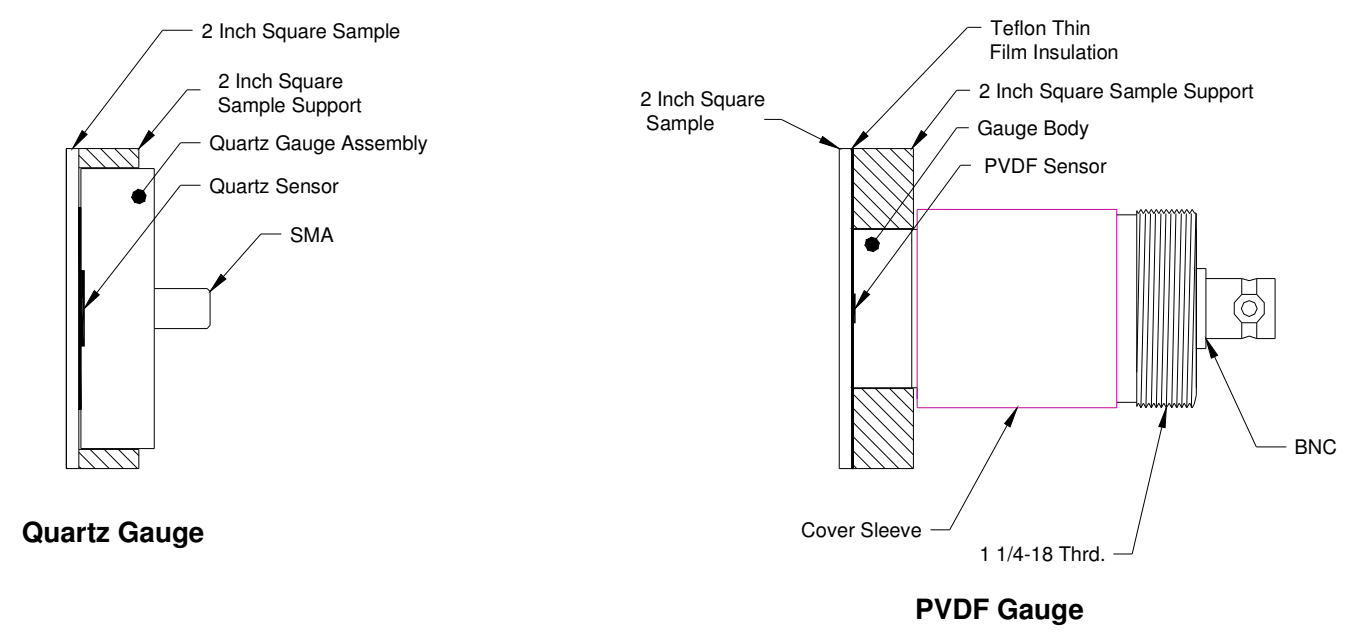

Figure 1. Quartz and PVDF Pressure Gauge with Sample

\subsection{Experiment Configuration}

The Lethality experiment target materials tested were 2024-T3 aluminum and Graphite Epoxy. The aluminum was testrd in the as received rolled condition to simulate real world conditions. This condition would have a thicker oxidation layer than if the samples were newly machined.

The PVDF gauge assembly was mounted in an adjustable fixture that allowed the target to be positioned a various fluence levels. Gauge mount, target assembly, and test chamber concepts are shown in Figures 2, 3 and 4. The gauge was in electrical contact with the target chamber through the target assembly conduit and through the coaxial cable shield and the vacuum feed through port.

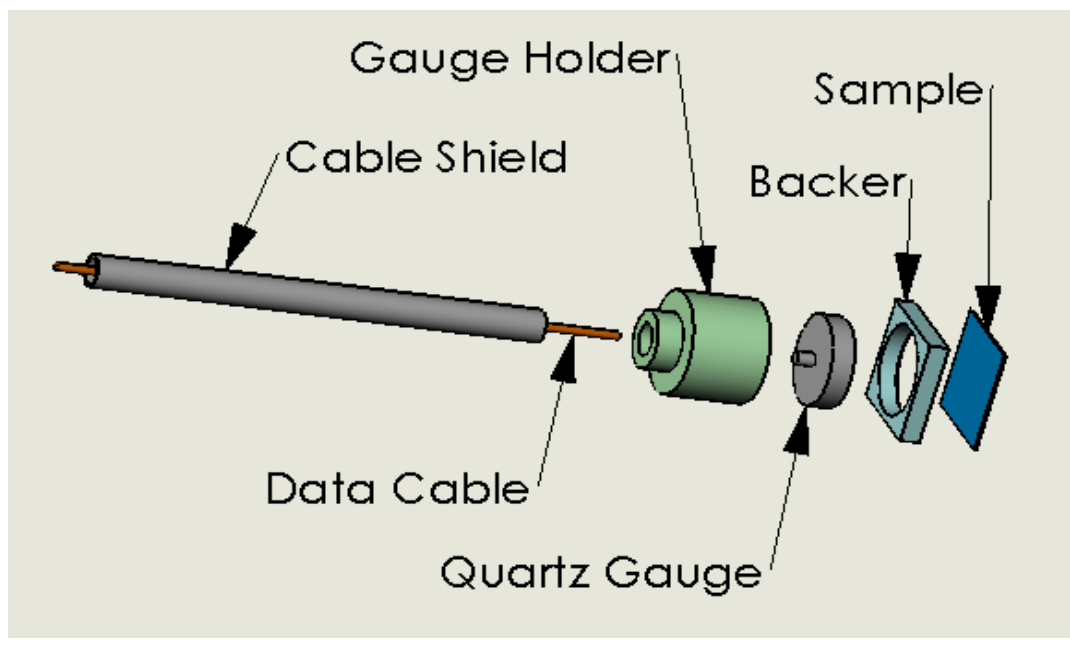

Figure 2a. Quartz Gauge mount configuration 


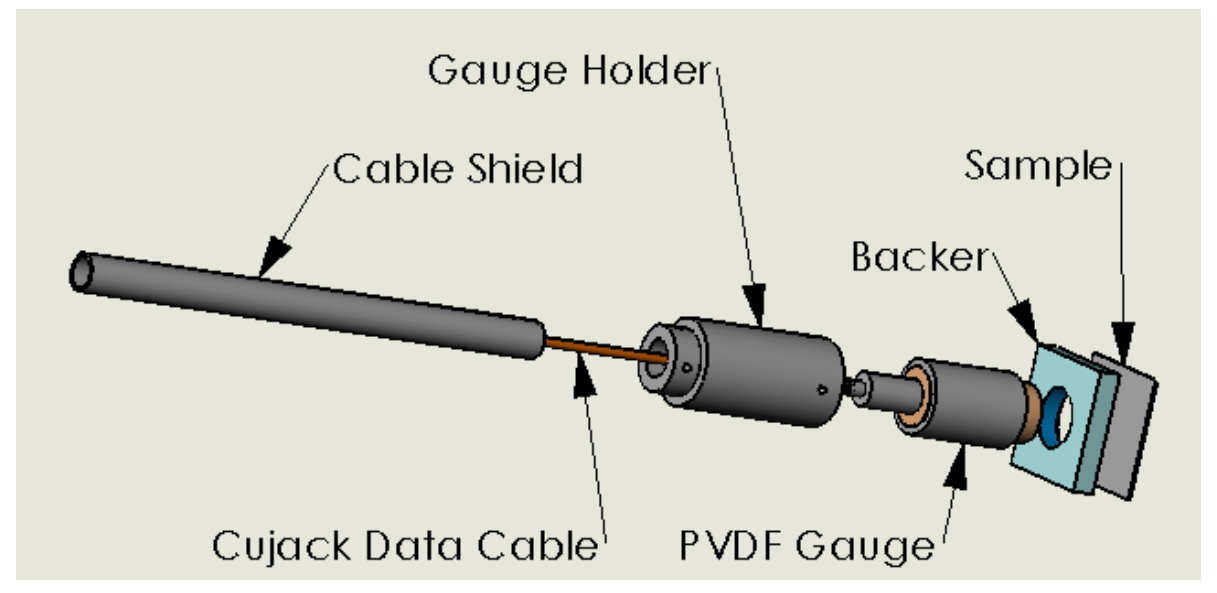

Figure 2b. PVDF Gauge mount configuration
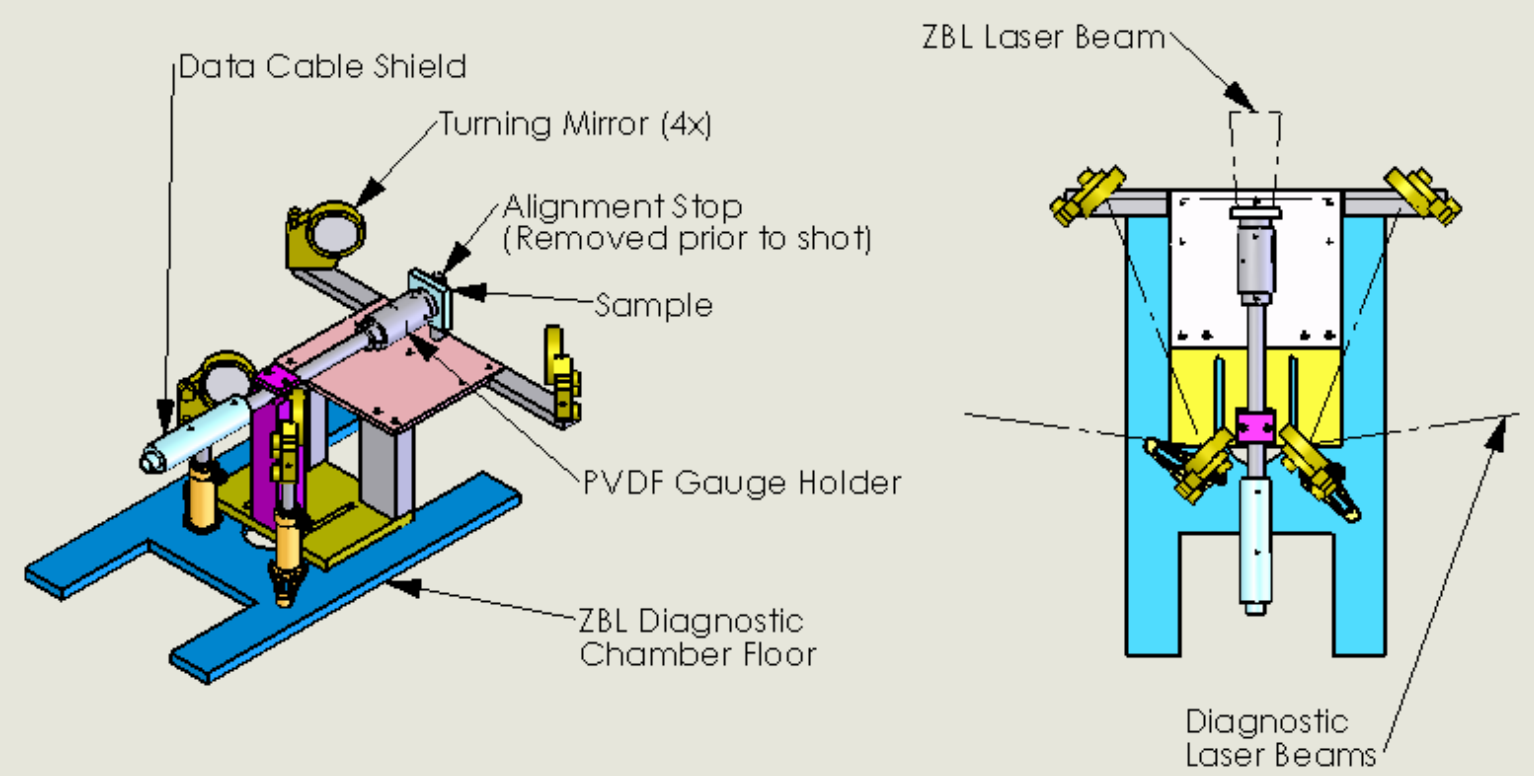

Figure 3. Target assembly to ZBL Chamber mounting hardware (PVDF Gauge shown) 


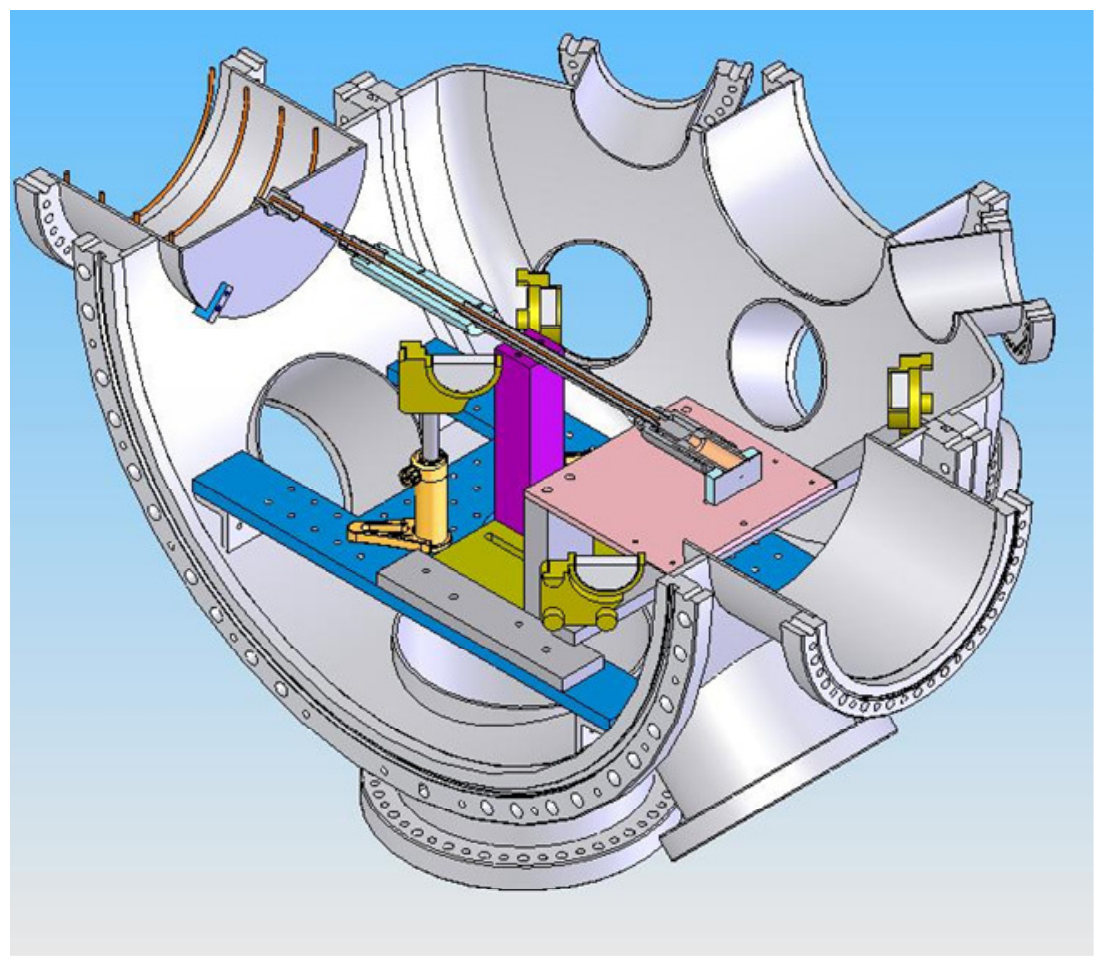

Figure 4. Target mounted in ZBL test chamber

\subsection{Test Results}

\subsection{Stress Gauge Results}

A full set of pressure time-history data plots and overlays are presented in this section. The data has been time corrected such that zero time corresponds to the laser timing pulse from the $2 \varpi$ detector plus the actual laser time of arrival at the front surface of the sample ( 5 to $10 \mathrm{~ns}$ later). The time of arrival in the plots therefore correspond to the transit time through the sample. The second pulse in the plots is from the stress wave ringing in the aluminum sample and provides additional information for model validation.

Table 1 summarizes the test results. Peak gauge stress, peak sample stress, incident fluence, and sample thicknesses are listed. Shots are paired up in the table to compare the stress transmitted through different sample thickness for a given Fluence. 
Table 1. Test Results Summary

\begin{tabular}{|c|c|c|c|c|c|c|c|}
\hline Test & Shot \# & $\begin{array}{l}\text { Fluence } \\
(\mathrm{J} / \mathrm{cm} 2)\end{array}$ & $\begin{array}{l}\text { Gauge } \\
\text { Type }\end{array}$ & $\begin{array}{l}\text { Sample } \\
\text { Mat'1 }\end{array}$ & $\begin{array}{l}\text { Nominal } \\
\text { Sample } \\
\text { Thickness } \\
(\mathrm{mm})\end{array}$ & $\begin{array}{l}\text { Peak } \\
\text { Gauge } \\
\text { Stress } \\
\text { (kbar) }\end{array}$ & $\begin{array}{c}\text { Peak } \\
\text { Sample } \\
\text { Stress } \\
\text { (kbar) }\end{array}$ \\
\hline 11 & B5111102 & 434 & QTZ & $\mathrm{Al}$ & 1 & 6.73 & 7.07 \\
\hline $12 * *$ & B5111105 & 455 & QTZ & $\mathrm{Al}$ & 1.5 & 6.29 & 6.6 \\
\hline $10 *$ & B5111008 & 480 & PVDF & $\mathrm{Al}-\mathrm{R} *$ & 1.5 & 2.88 & 6.92 \\
\hline 9 & B5111005 & 398 & PVDF & $\mathrm{Al}$ & 0.5 & 3.47 & 8.33 \\
\hline 4 & B5110808 & 378 & PVDF & $\mathrm{Al}$ & 2 & 2.19 & 5.26 \\
\hline 1 & B5110705 & 196 & PVDF & $\mathrm{Al}$ & 2.5 & 1.81 & 4.35 \\
\hline $7 *$ & B5110908 & 200 & PVDF & $\mathrm{Al}-\mathrm{R}^{*}$ & 2.5 & 1.55 & 3.73 \\
\hline 3 & B5110805 & 115 & PVDF & $\mathrm{Al}$ & 1.5 & 1.74 & 4.18 \\
\hline 2 & B5110802 & 73 & PVDF & $\mathrm{Al}$ & 1 & 1.88 & 4.52 \\
\hline 6 & B5110905 & 86 & PVDF & $\mathrm{Al}-\mathrm{R} *$ & 1 & 1.78 & 4.28 \\
\hline 8 & B5111004 & 429 & PVDF & Gr-Ep & 1.5 & 1.72 & $\sim 1.7$ \\
\hline \multicolumn{8}{|c|}{\begin{tabular}{l|l|l|l|l|l} 
Notes: & & & & & \\
\end{tabular}} \\
\hline \multicolumn{8}{|c|}{ * Al-R* Sample material indicates sample was re-used (i.e. shot twice) } \\
\hline \multicolumn{8}{|c|}{ ** Laser pulse width was $1.5 \mathrm{~ns}$ on all shots except on Shot 12 it was $0.7 \mathrm{~ns}$} \\
\hline \multicolumn{8}{|c|}{$\begin{array}{l}\text { Peak sample stress determination: Aluminum stress }=\sim 2.4 \text { times the gauge stress for PVDF and } \\
\sim 1.05 \text { times the gauge stress for quartz. }\end{array}$} \\
\hline \multicolumn{8}{|c|}{ Quartz gauge stress represents average fluence over the 12-mm dia sensor area. } \\
\hline \multicolumn{8}{|c|}{$\begin{array}{l}\text { Peak PVDF gauge stress is based on thin gauge mode reduction for Shot } 8 \text { and on thick gauge mode } \\
\text { reduction for all other shots. }\end{array}$} \\
\hline
\end{tabular}


Figure 5 is an overlay of Shots 3 and 10. Both were 1.5-mm samples but at different fluences. Shot 10 was the second test on that sample. Note that the pulse width (impulse) on the shot at $480 \mathrm{~J} / \mathrm{cm} 2$ is significantly wider than on the $115 \mathrm{~J} / \mathrm{cm} 2$ shot.

Figure 6 is an overlay of Shots 9,10 , and 4 at $\sim 400 \mathrm{~J} / \mathrm{cm} 2$ with $0.5,1.5$, and $2.0 \mathrm{~mm}$ aluminum samples, respectively. Shot 10 was the second test on that sample. This data set shows the attenuation of peak stress with distance. The second pulse on the gauges is a reflection of the first shock off the sample gauge interface. The time of arrival of this reflected wave corresponds to the two way transit time of the shock through the sample. Also the arrival of the first shock reflection ringing in the aluminum sample correlates well with sample thickness.

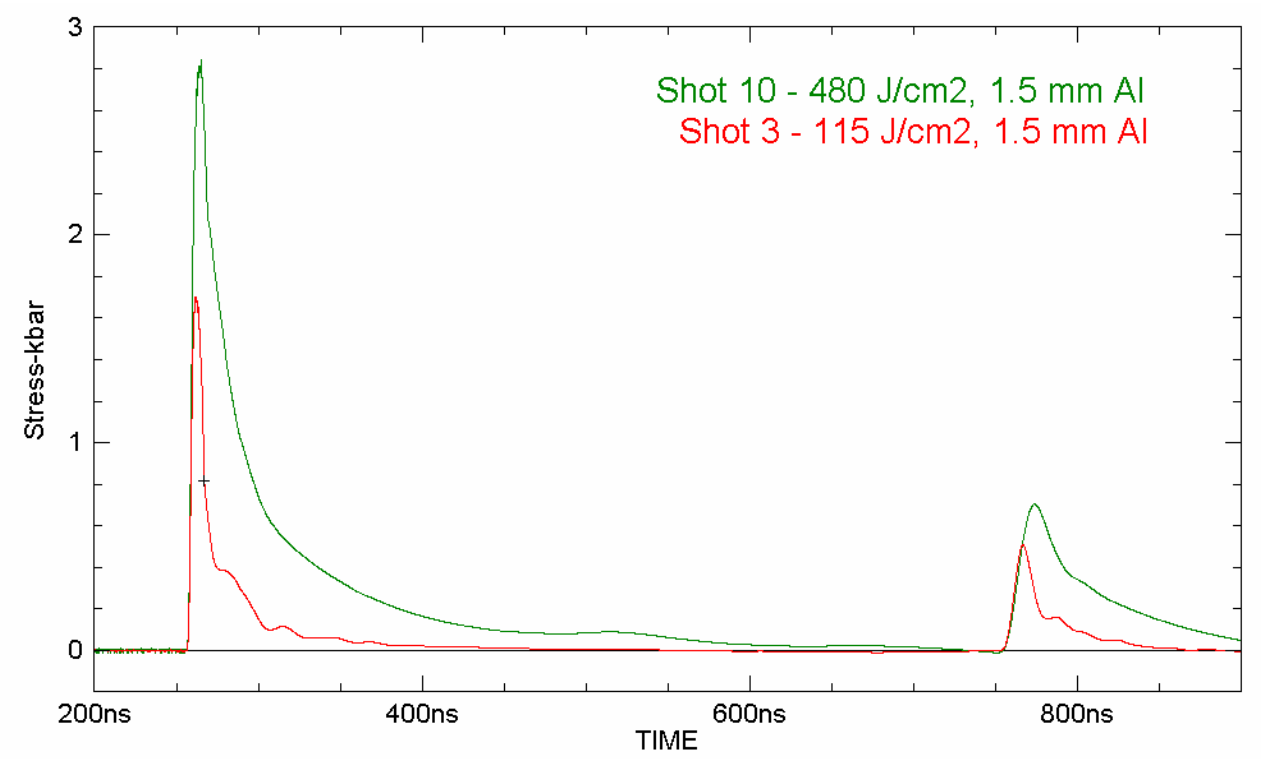

Figure 5. Data plot showing shots 3 and 10 overlaid

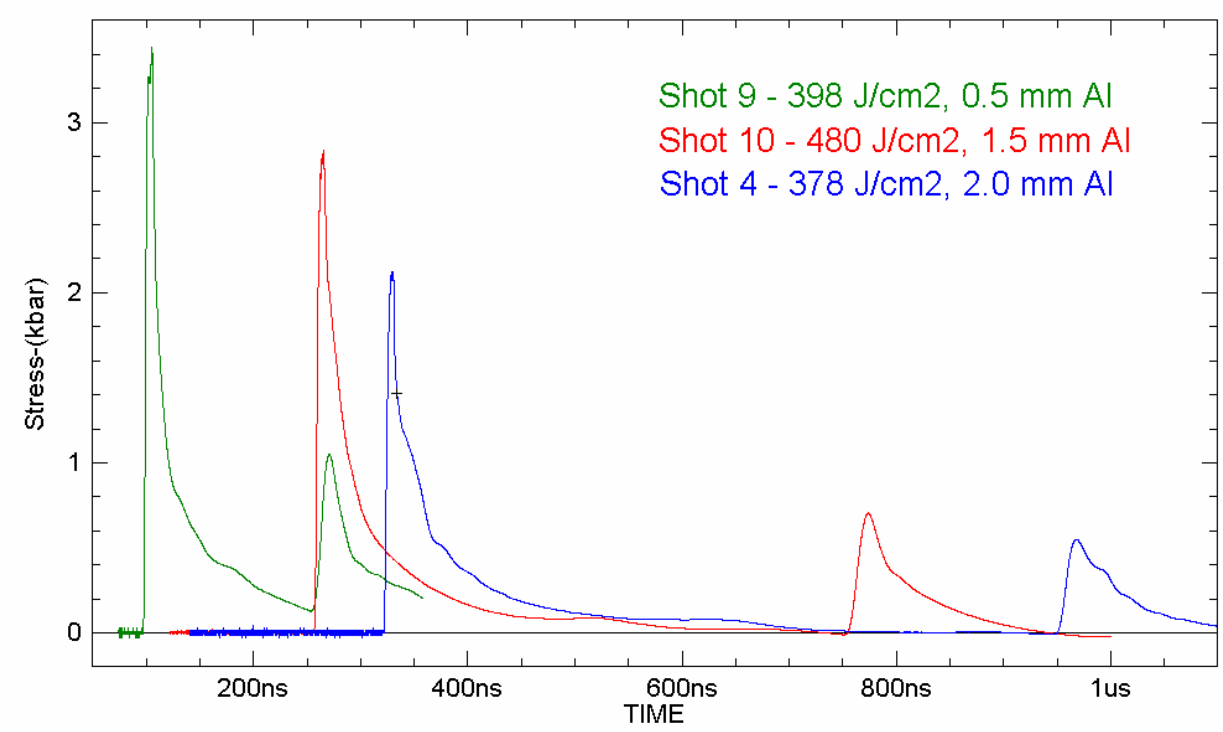

Figure 6. Data plot showing shots 9, 10, and 4 overlaid

TR06-24 Draft 
Figure 7 is an overlay of Shots 1 and $7(\sim 200 \mathrm{~J} / \mathrm{cm} 2,2.5 \mathrm{~mm} \mathrm{Al})$. This $2.5 \mathrm{~mm}$ sample was shot twice; first on Shot 1 and then on Shot 7. Figure 8 is an overlay of Shots 2 and 6 $(\sim 200 \mathrm{~J} / \mathrm{cm} 2,1 \mathrm{~mm} \mathrm{Al})$. Shot 2 was the first test and Shot 6 was the second test on this $1 \mathrm{~mm}$ thick sample.

Note in both comparisons that the pulse width on the second test is narrower and the peak stress is lower. The wave profiles are quite similar which indicates that the sample did not incur spall damage. The samples would not be expected to produce rear surface spall at these low stress levels. The spall strength of 2024 aluminum is about $16 \mathrm{~kb}$ for $\mathrm{T} 4 \mathrm{and}$ about $13 \mathrm{~kb}$ for $\mathrm{O}$ temper. The material tested was 2024-T3

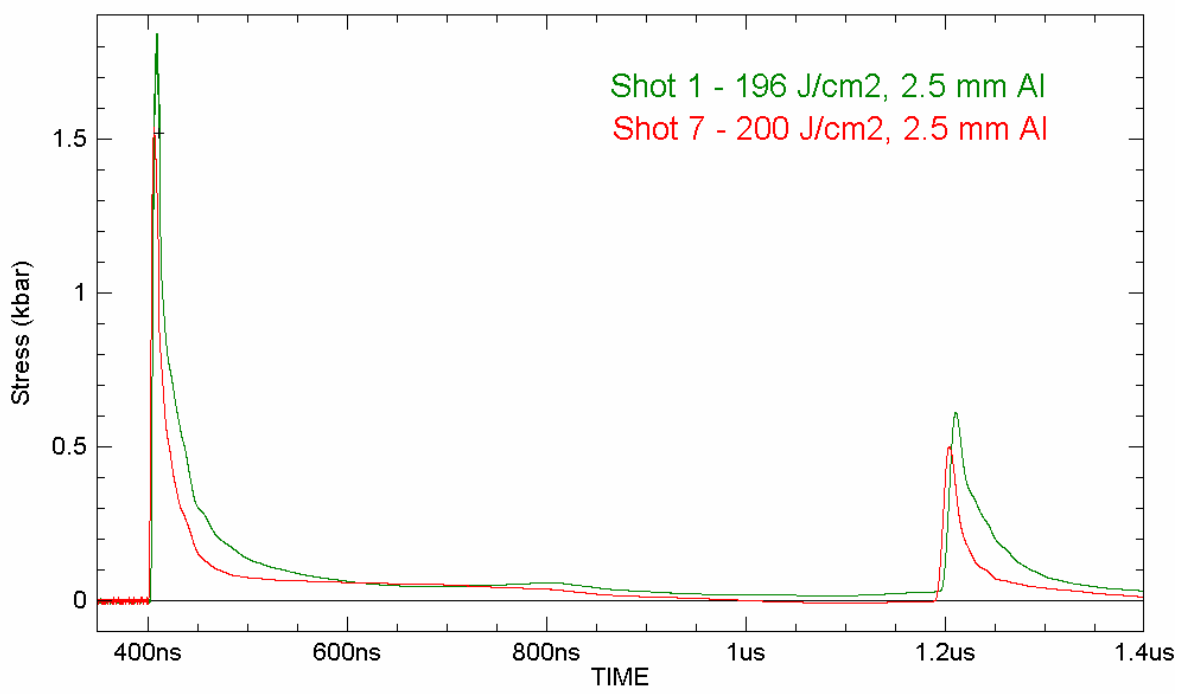

Figure 7. Data plot showing shots 1 and 7 overlaid

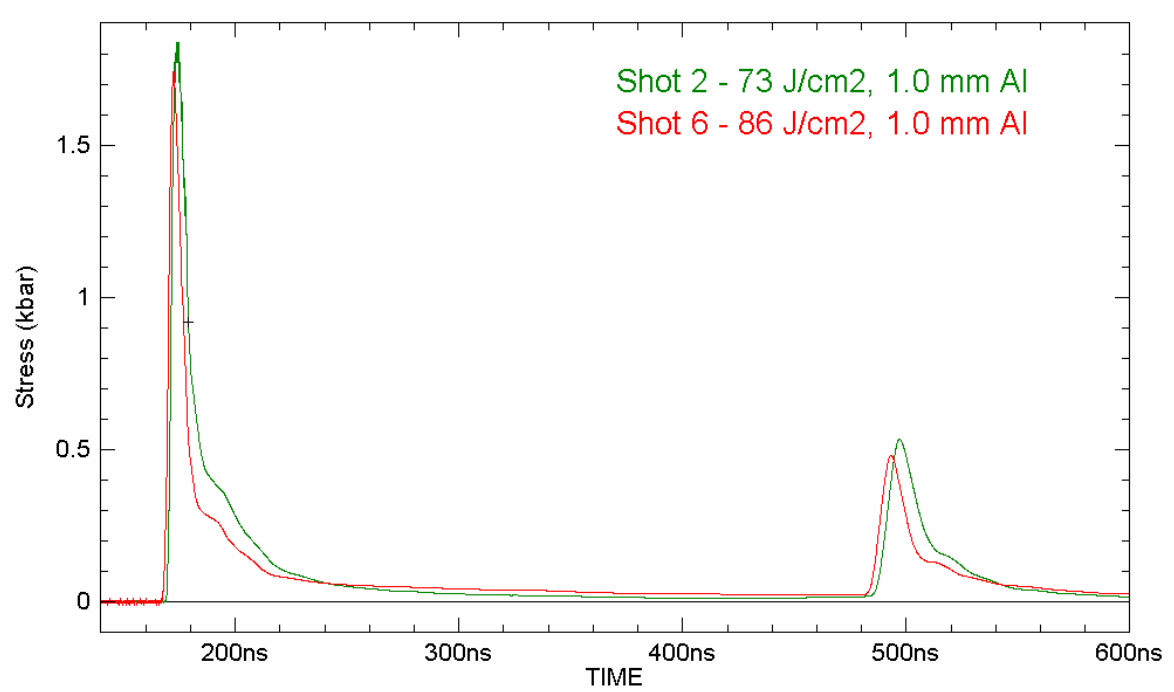

Figure 8. Data plot showing shots 2 and 6 overlaid 
Figure 9 is an overlay of PVDF gauge stress profiles for shots 9, 2, and 7; for 0.5, 1.0, and 2.5 thick aluminum samples, respectively. Fluence and sample thickness was different on each shot; nevertheless, the data looks consistent.

Figure 10 is an overlay of the Quartz gauge data for shots 11 and 12 . When looking at the samples for these two shots, there was a 6-mm diameter hot spot in the center of the 15$\mathrm{mm}$ square spot size. The diameter of the sensor is $12 \mathrm{~mm}$, so the quartz gauge measures the average stress across the beam diameter where as the smaller $3 \times 3$-mm PVDF gauge sensor can measure the average stress of the hot spot in the center of the beam.

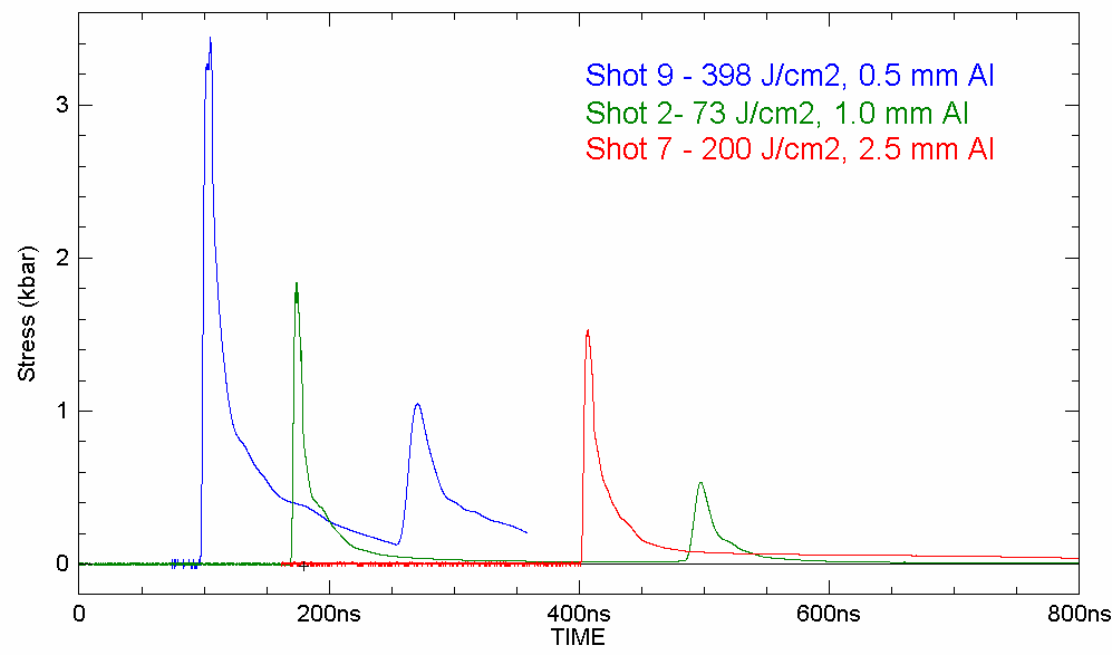

Figure 9. Data plot showing shots 2, 7, and 9 overlaid

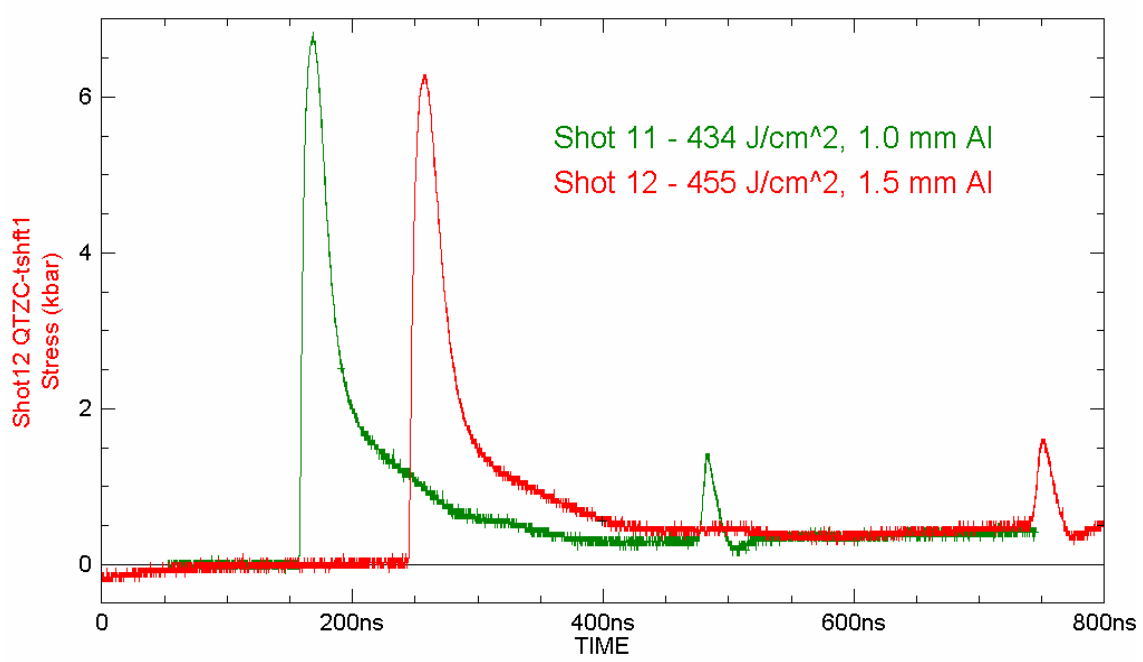

Figure 10. Data plot showing shots 11 and 12 overlaid 
Figure 11 is an overlay of the PVDF and the Quartz gauge data for Shots 10 and 12. The comparison is for $1.5-\mathrm{mm}$ aluminum sample at a nominal fluence of $400 \mathrm{~J} / \mathrm{cm} 2$. To make this comparison, the stress profiles were scaled to convert from peak gauge stress to peak sample stress as was done in Table 1. The similarity in the two profiles indicates good correlation between measurement techniques.

Figures 12 through 17 show individual plots records for shots: 1, 3, 4, 6, 8, and 10 .

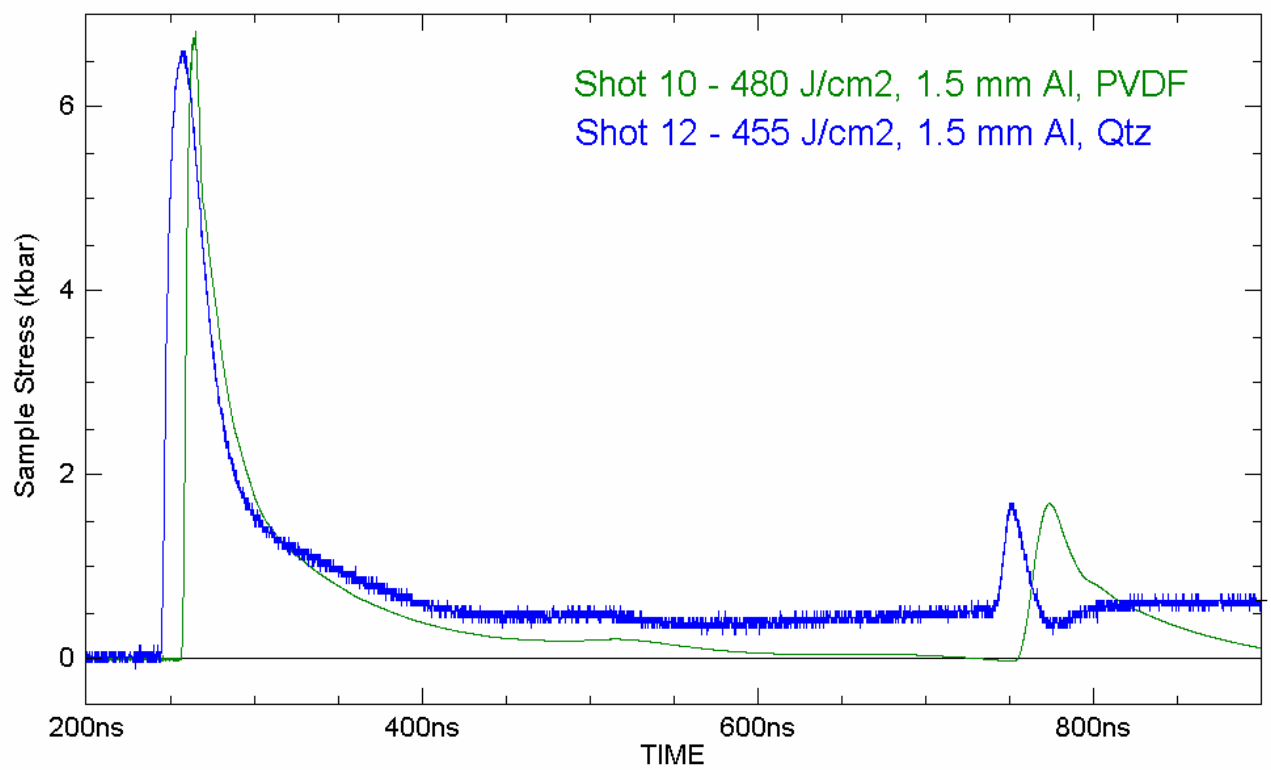

Figure 11. Data plot comparing PVDF shot 10 and Quartz gauge shot 12.

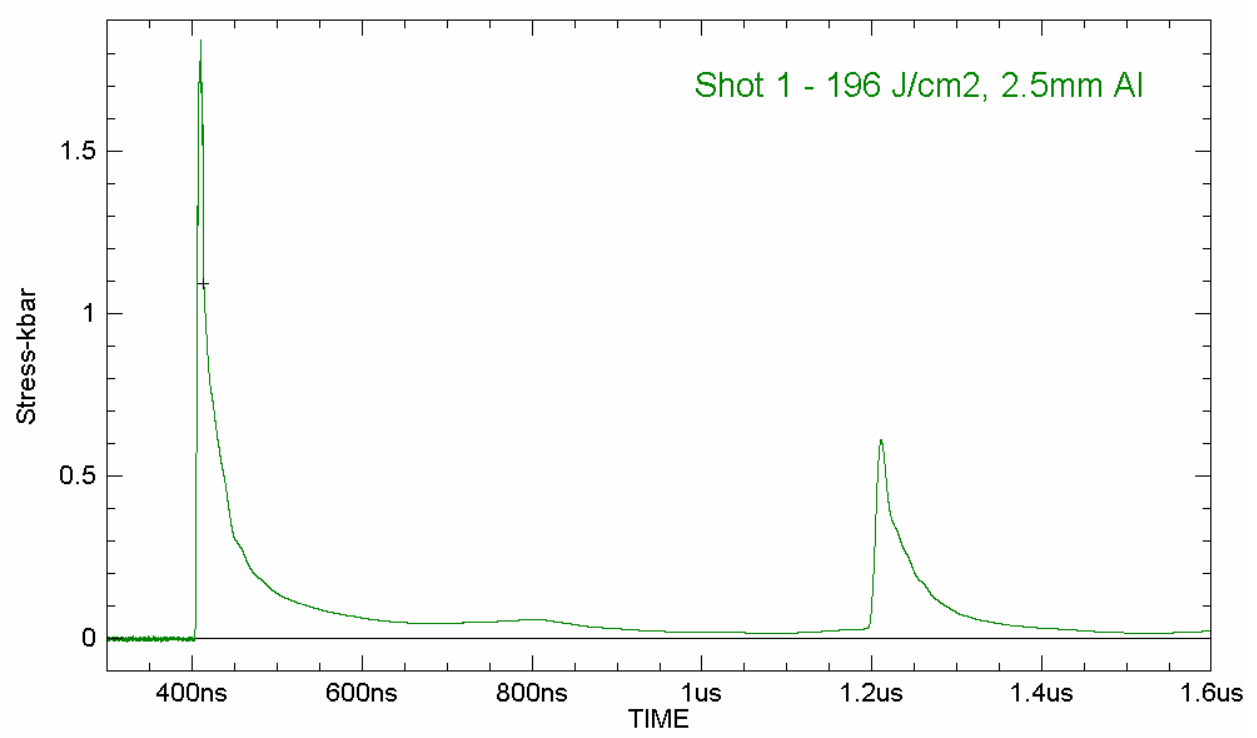

Figure 12. Data plot showing shot 1 


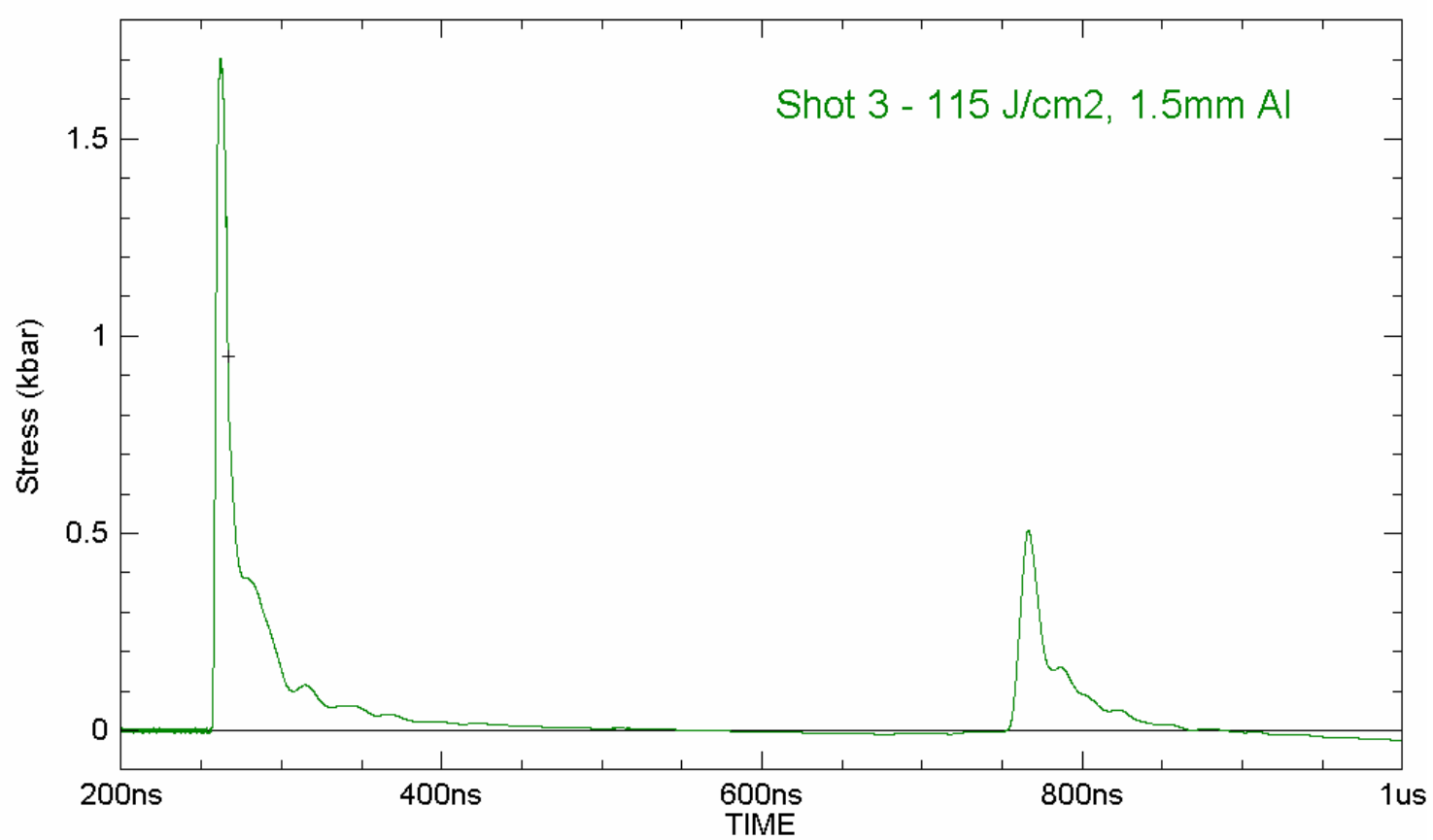

Figure 13. Data plot showing shot 3

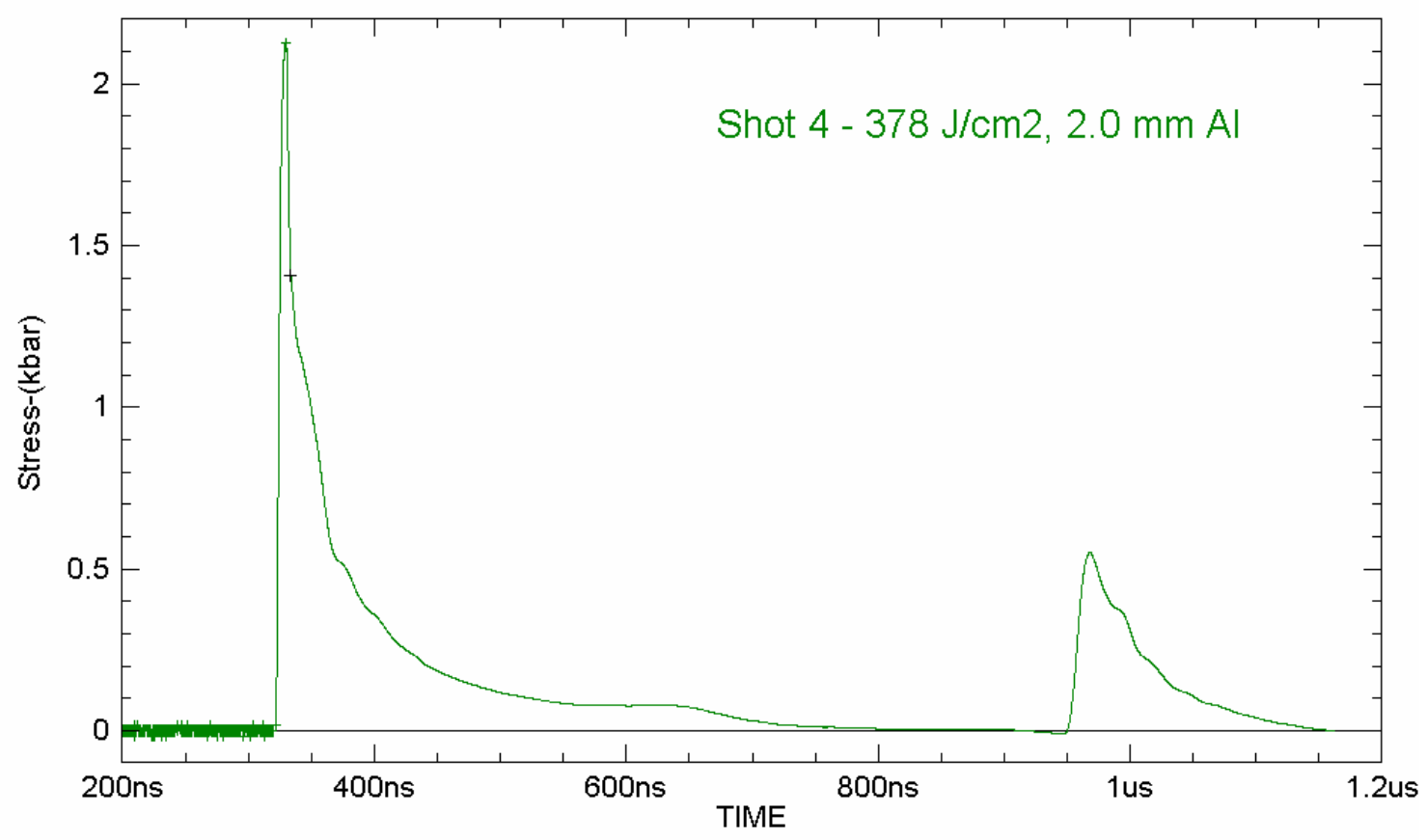

Figure 14. Data plot showing shot 4 


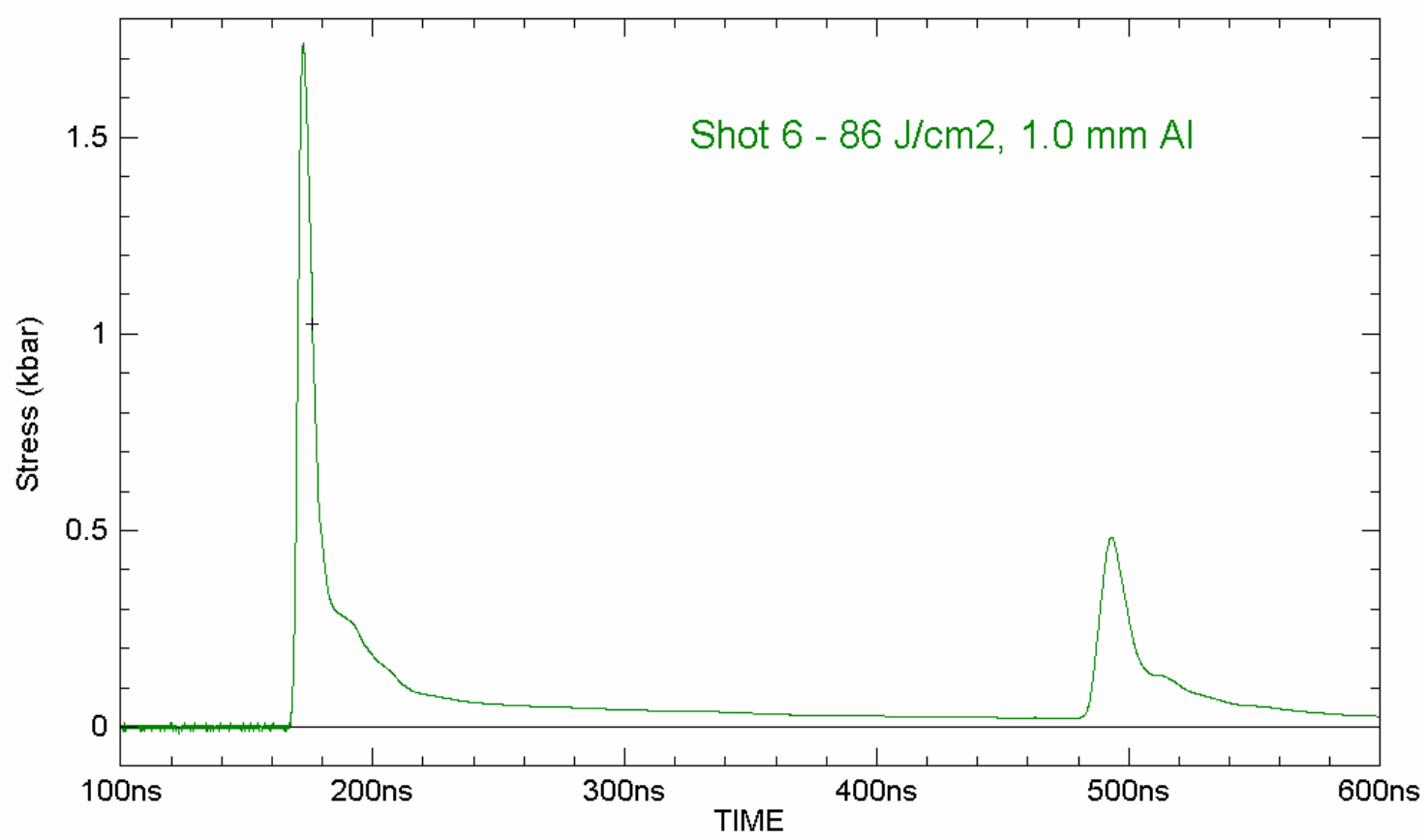

Figure 15. Data plot showing shot 6

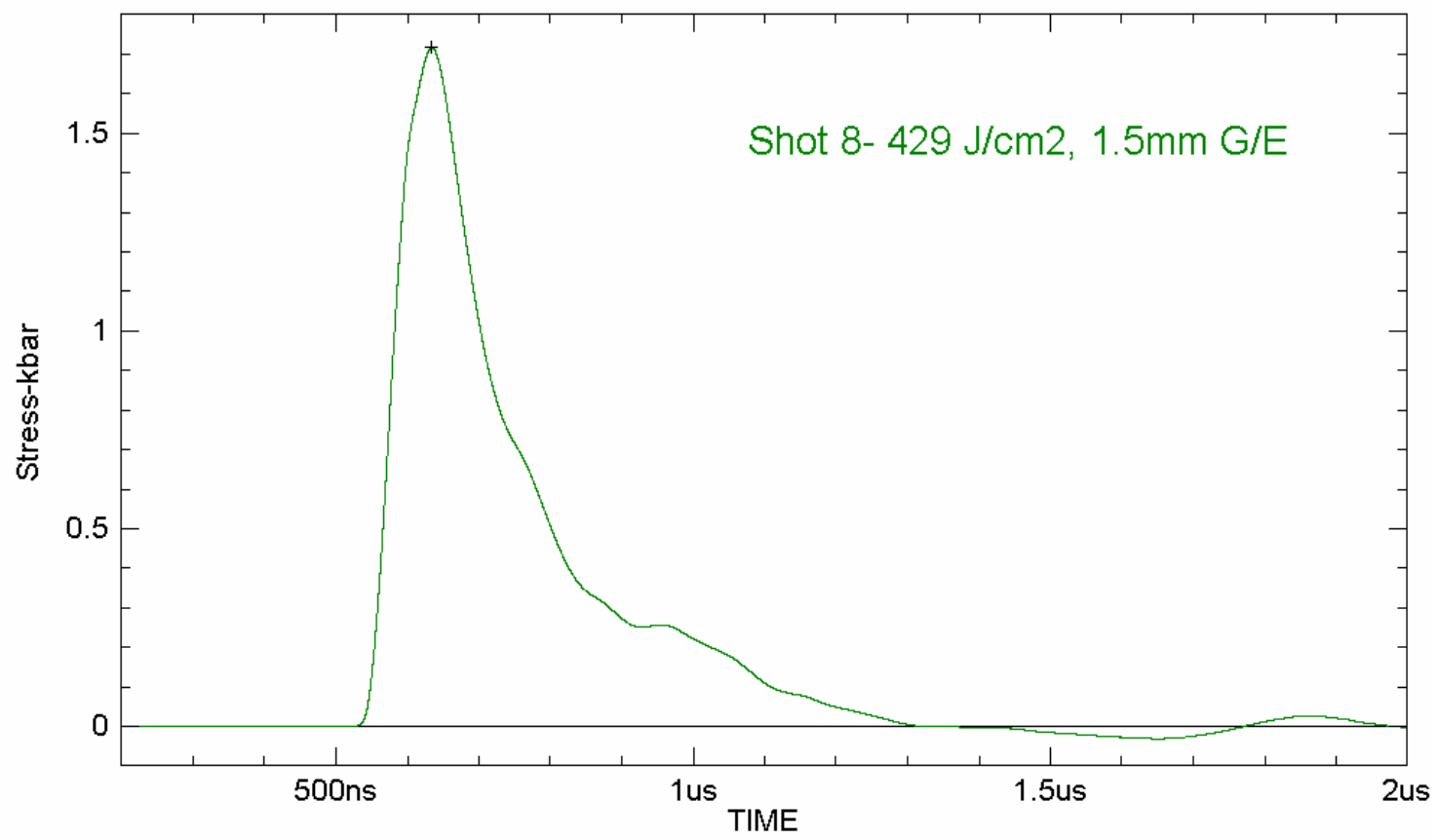

Figure 16. Data plot showing shot 8 


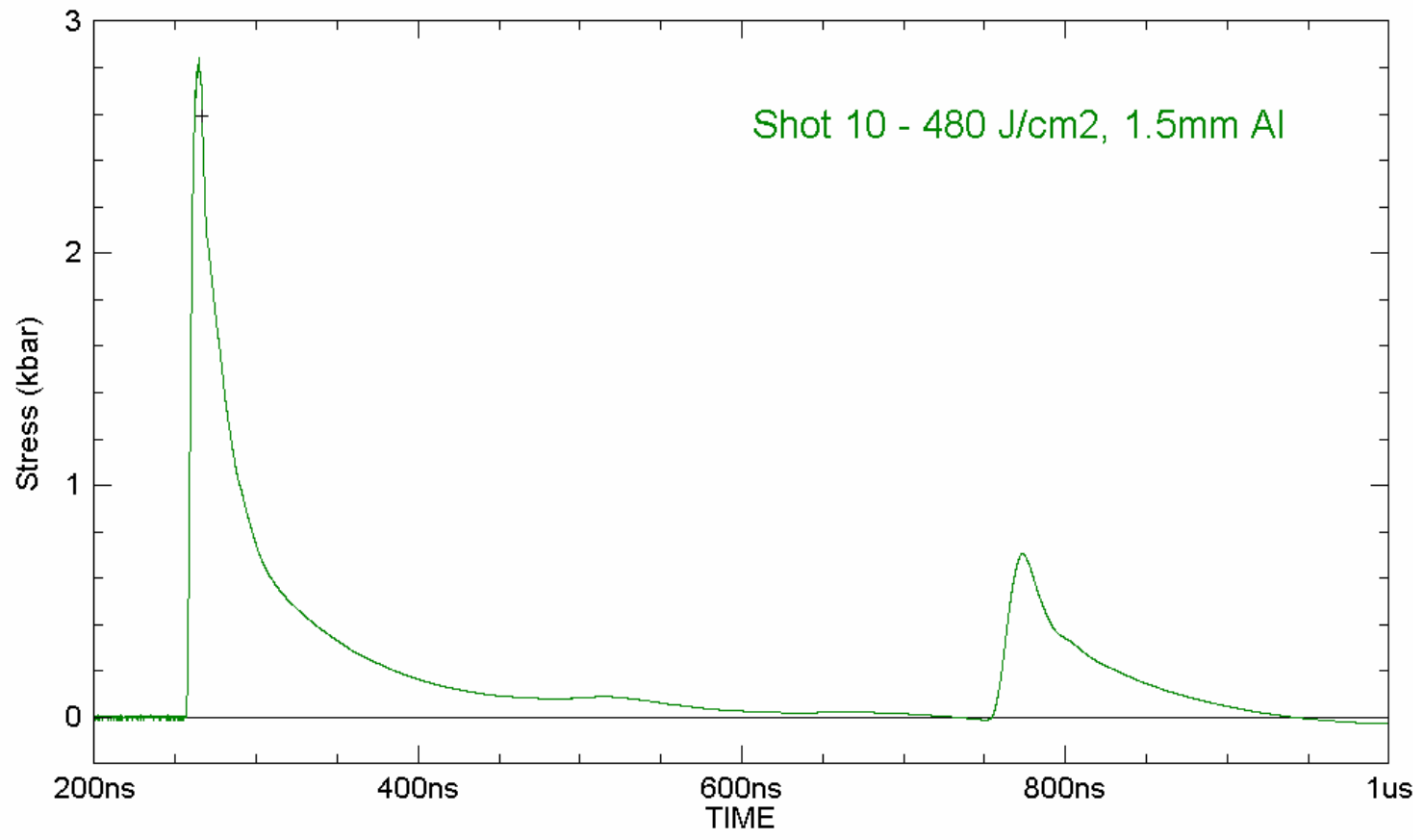

Figure 17. Data plot showing shot 10 
Figure 18 is a graph of aluminum stress vs. sample thickness for the $\sim 400 \mathrm{~J} / \mathrm{cm} 2$ shots. As expected it shows the trend for peak stress attenuation with propagation distance. Keep in mind that the Fluence for this set of shots ranges from 378 to $480 \mathrm{~J} / \mathrm{cm} 2$. Also as indicated on the plot, one of the shots was conducted with a laser pulse of $0.7 \mathrm{~ns}$ whereas all of the others were $1.5 \mathrm{~ns}$.

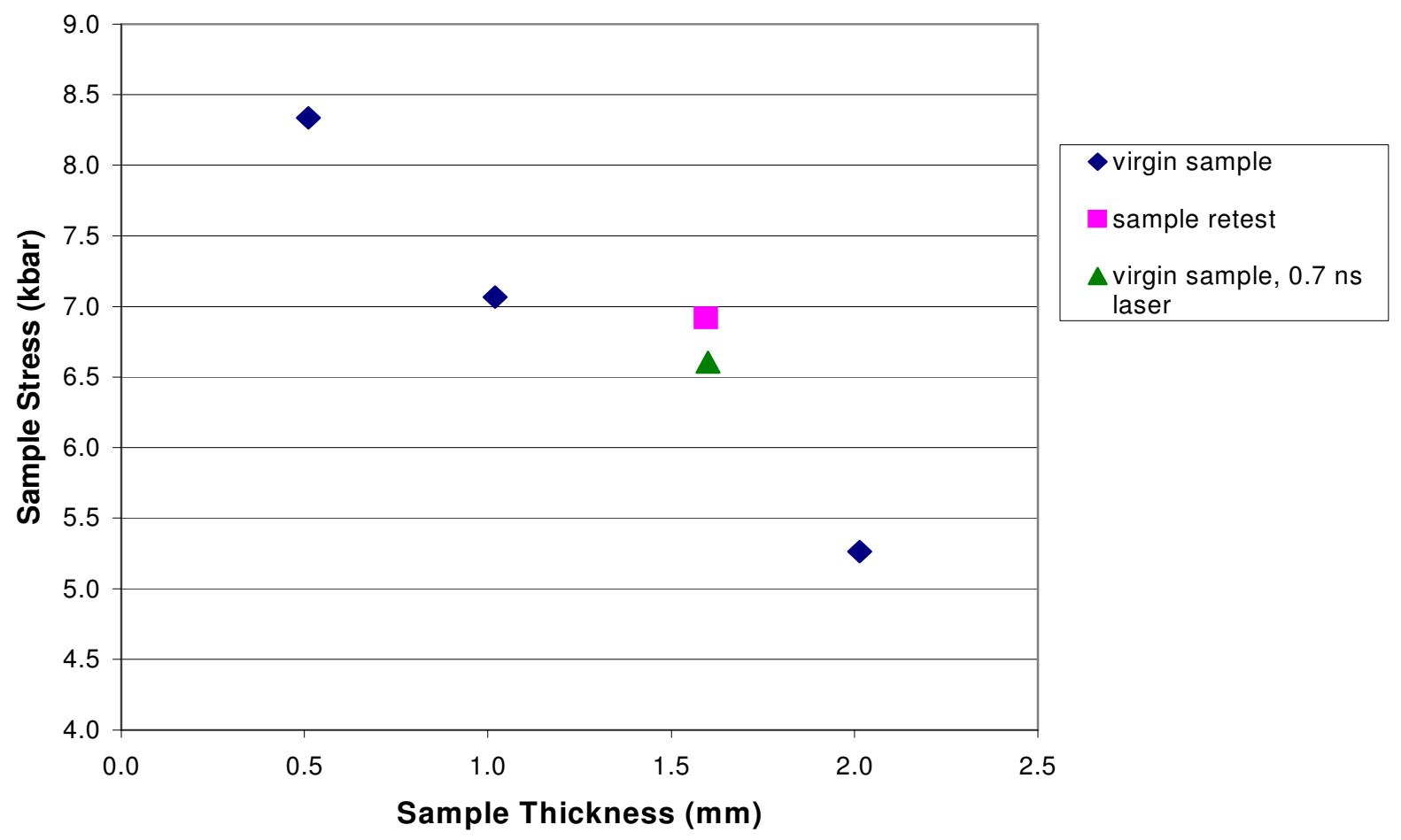

Figure 18. Graph of Sample Stress vs. Thickness @ 400 J/cm² 


\subsection{Ablation Data Results}

The samples have multiple burn patterns from a single shot that reveal ZBL beam characteristics. The laser beam directed to the target comes from a turning mirror that is AR coated to separate (pass) the infrared (1ひ) beam and turn the primary green $(2 \omega)$ beam toward the target. The mirror also tuns a fraction of infrared (1ひ) beam (along with the green) equal to 1 or $2 \%$ of the total beam energy at the target. The photograph in Figure 19, shows 3 square deposition images overlapping on the Shot 12. The image in the center is $1.5 \mathrm{~cm}$ square and is the ablated surface from the primary $2 \omega$ beam. The larger beam in the photo (surrounding the $2 \omega$ beam) is about $2.5 \mathrm{~cm}$ square and was produced by the $1 \varpi$ beam. The third image offset to the right is believed to be a reflection off of the second surface of the turning mirror and contains $<1 \%$ of the total beam energy (Ref. Ian Smith, SNL).

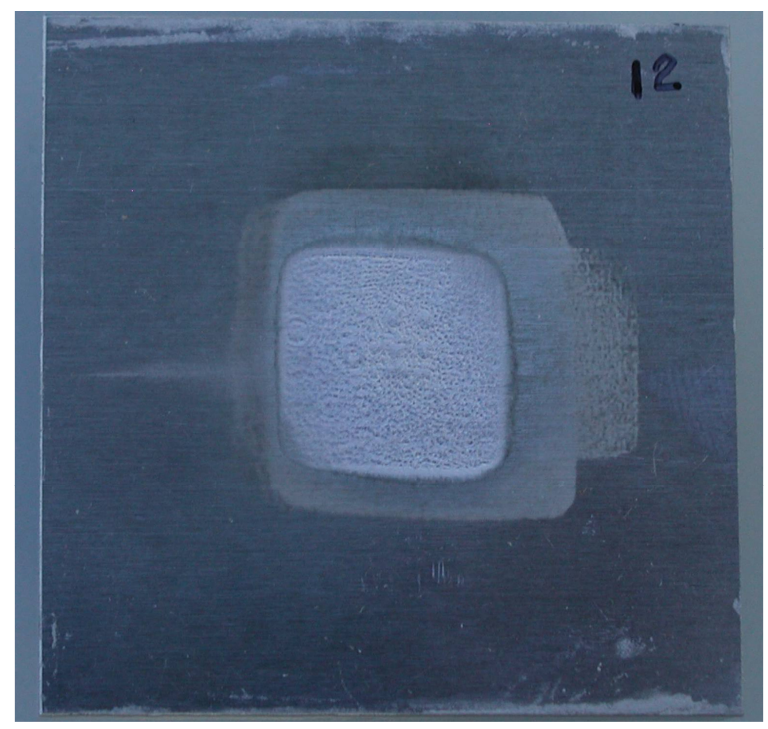

\section{Figure 19. Ablated surface from Shot 12 shows multiple beam depositions}

The ablated surfaces were measured with a non contact profilometer, as described in Appendix B.. The energy deposited in the front surface by the $1 \omega$ and $2 \varpi$ beams apparently produced a bending moment in the sample causing permanent deformation, as indicated by the convex shape in the surface profiles shown in Figure 20. The samples were initially reasonably flat. Flatness of one $1.5-\mathrm{mm}$ thick sample was flat within 0.1 mil ( $2.5 \mathrm{um}$ ) across a $20-\mathrm{mm}$ diameter and flat within 0.2 to 0.3 mils (5 to 8-um) across the full 51-mm square sample. Ablation depth and crater depth estimates are given in Table 2 along with thermal distortion measurements for four shots $(4,10,11$, and 12) at nominally $411 \mathrm{~J} / \mathrm{cm} 2$. These estimates were taken from the 2D profile plots in Figure 20. Additional ablation measurements are presented in Appendices B and C.

The non-uniform ablated surface contains 40-um-deep craters near the center, 5 to 10-um deep craters on the left side, and 20-um deep craters on the right side. The right side of Shot 12 is ablated more that the left side, which may in part, be due to the third image overlapping on the right side. Most of the relatively smooth surfaces on the far left 
and far right sides (outside of the $2 \varpi$ ablated region) were exposed to the $1 \varpi$ beam, but the Shot 12 profile does not show any signs of detectable erosion even though the foot print shows up in the photographs. Shot 11 is similar.

The samples in both shots 11 and 12 were backed up by 32-mm diameter quartz in the Ktech Quartz gauge. All other samples, including Shots 4 and 10, were backed up with the PVDF gauge, which is a more compliant backing. The baking material may influence crater depth as the local lateral shock focusing and rear surface confinement may play a role in the plugging process that forms the deep craters.

The 32-mm diameter quartz provided a larger backing surface than the 19-mm diameter Kel-F backer on PVDF gauges did. It appears that on Shot 4 there is some surface displacement around the perimeter (out side of the Kel-F backer) possibly from the $1 \mathrm{w}$ beam impulse or from ablation. The displacement is at the edge of the $1 \mathrm{w}$ beam located at 2 and 26-mm (Figure 20, Shot 4) and is superimposed on the convex surface. This is where the thermal bending starts. This is less evident on shot 10, but shot 10 was shot twice, first at $125 \mathrm{~J} / \mathrm{cm} 2$ (larger beam diameter) and second and $\sim 400 \mathrm{~J} / \mathrm{cm} 2$. Also, the sample was pre-conditioned by the first shot and the coupling factor may have be different on the second shot which might affect ablation and stress generation. Further analysis would require detailed sample inspection, modeling and a better estimate of the 1 $\varpi$ beam energy.

Table 2. Sample distortion and Ablation depth estimates at $\sim 400 \mathrm{~J} / \mathrm{cm} 2$

\begin{tabular}{|c|c|c|c|c|c|}
\hline Shot & $\begin{array}{c}\text { Sample } \\
\text { Thickness } \\
(\mathrm{mm})\end{array}$ & $\begin{array}{c}\text { Thermal } \\
\text { Distortion } \\
(\mathrm{um})\end{array}$ & $\begin{array}{c}\text { Approximate } \\
\text { Ablation } \\
\text { depth, (um) }\end{array}$ & $\begin{array}{c}\text { Ablation } \\
\text { Crater } \\
\text { depth } \\
\text { (um) }\end{array}$ & $\begin{array}{c}\text { Gauge } \\
\text { Type }\end{array}$ \\
\hline 4 & 2 & 20 & 5 & 10 & PVDF \\
\hline 10 & 1.5 & 25 & 10 & 20 & PVDF \\
\hline 11 & 1 & 80 & 20 & 40 & Quartz \\
\hline 12 & 1.5 & 60 & 20 & 40 & Quartz \\
\hline
\end{tabular}




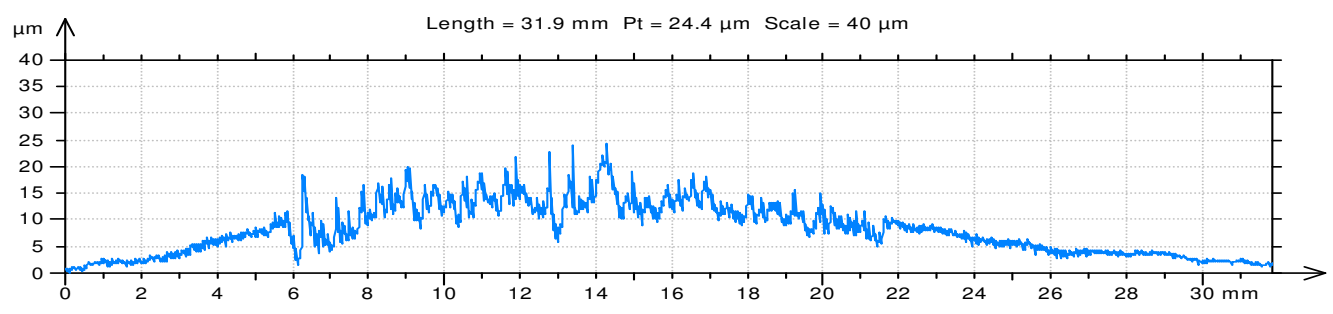

Extracted Profile (north to south) of Leveled Data at $X=13.2 \mathrm{~mm}$

Shot 4

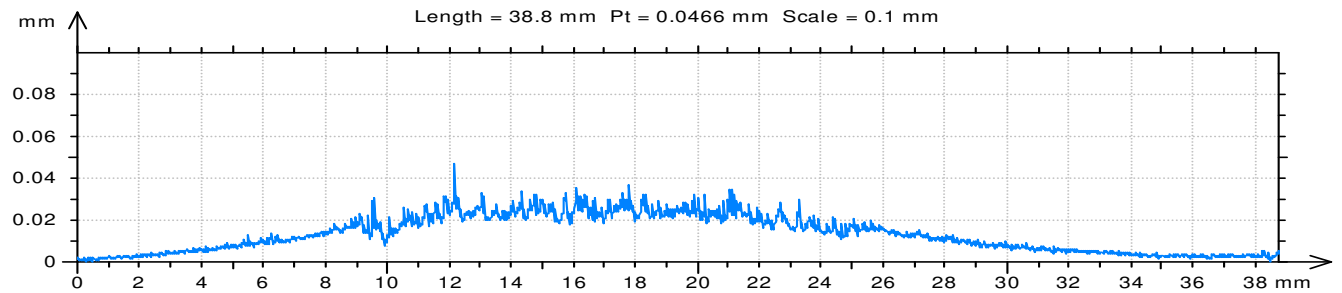

Extracted Profile (north to south) of Leveled Data at $X=17.1 \mathrm{~mm}$

Shot 10

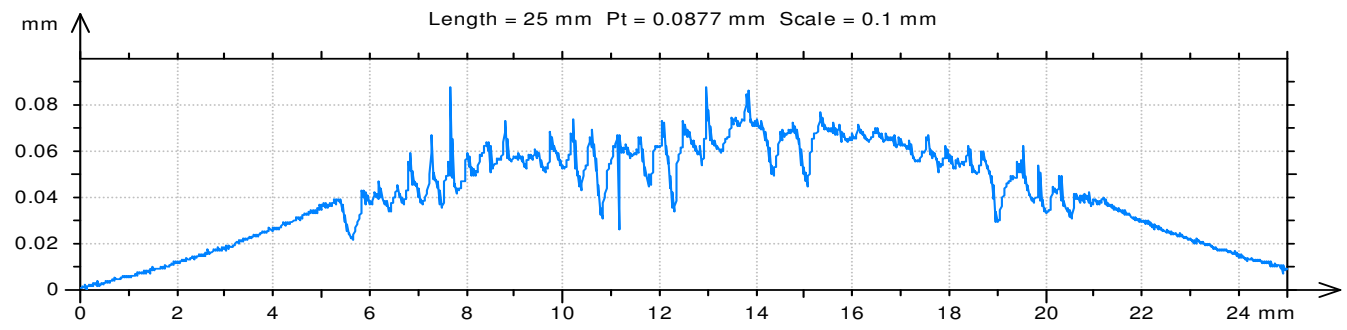

Extracted Profile (north to south) of Leveled Data at $X=12.5 \mathrm{~mm}$

Shot 11

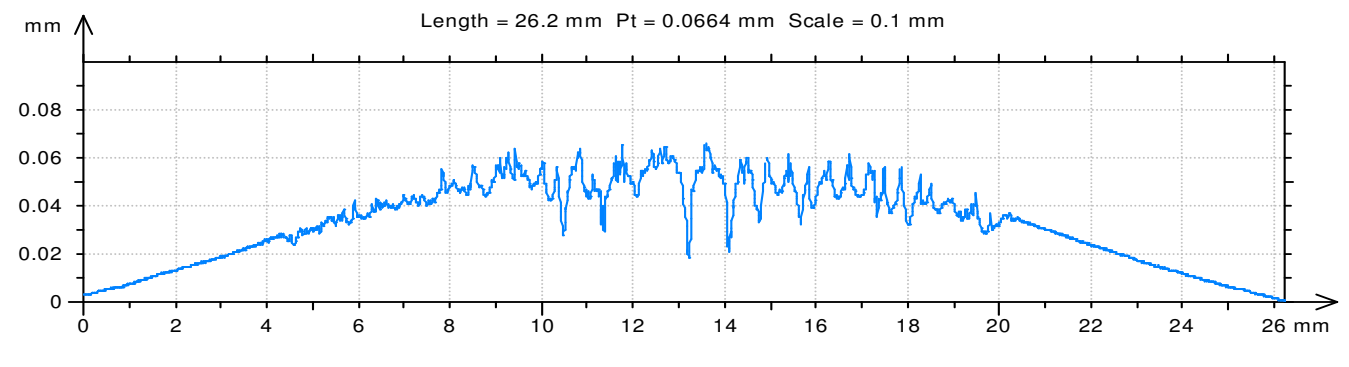

Extracted Profile (north to south) of Leveled Data at $X=12.0 \mathrm{~mm}$

Shot 12

Figure 20. Surface profiles show ablation depth and thermal distortion for four shots $(4,10,11$, and 12) at nominally $411 \mathrm{~J} / \mathrm{cm} 2$. Profiles were taken left to right relative to photographs. 


\subsection{Conclusions}

The PVDF and quartz gauges measured the stress wave transmitted to the sample rear surface. Pressure pulse voltage signals were very low and the measurements were successful in spite of the machine or experiment induced baseline shift, albeit small. Base line noise was only $1 \mathrm{mV}$ peak-to-peak on the sensitive scope channel. The gauges and cables in the chamber were shielded with conduit and resulted in high fidelity signals.

The stress measurements show a clear trend of peak stress attenuation with propagation distance, as would be expected. The aluminum sample stresses measured were in the 4 to $8 \mathrm{Kbar}$ range, which is around the $6 \mathrm{kbar}$ yield strength of Aluminum. The attenuation curve will tend to flatten when the shock attenuates down to the yield strength as it propagates through the sample. This constitutes a good data set for model validation.

VISAR was considered as a diagnostic for this test series but predicted stress levels were uncertain and we had had good success previously with PVDF at this test facility; plus the aggressive test schedule and limited number of shots left little opportunity to set up this diagnostic. The PVDF gauge on Shots 10 and the Quartz gauge on Shot 12 measured very similar shock pulses with $1.5-\mathrm{mm}$ thick $2024-\mathrm{T} 3$ samples at fluences of 480 and $455 \mathrm{~J} / \mathrm{cm} 2$, respectively. The similarity in the two profiles indicates good correlation between measurement techniques. In addition, these two sensors have different sensor sizes and average the stress from different parts of the beam. The similarity in the measured stress pulses indicates the laser induced blow-off pulses were relatively uniform and repeatable.

The laser beam ablated the front surfaces of the samples. Surface profile measurements of the ablated surface were used to estimate the depth of material removed. Ablated samples indicate a hot spot in the center where craters were formed; so the beam energy is not totally uniform across the diameter. This should be considered when evaluating ablation depth vs. beam energy.

\subsection{Recommendations}

This test series provides important data sets that can used for code validation and should be used to design future experiments. We recommend the following:

- Test thinner samples to stay well above the yield strength of aluminum and provide better sensitivity to laser coupling factor.

- Each sensor type has advantages and disadvantages. Consider using more than one type of sensor in future tests. (For instance, Ktech has successfully fielded PVDF and VISAR on the same small diameter sample. Also, both PVDF and Quartz were used successfully on this test series.)

- Conduct further analysis of sample ablation depth at key locations and determine the beam energy at that location.

- Investigate the affect of backing material on ablation depth and crater formation. 
Appendix A: Photographs of ablated surface of samples.

Photographs of the ablated surface of aluminum and graphite epoxy test samples are presented. Fluence values listed in this section are nominal.
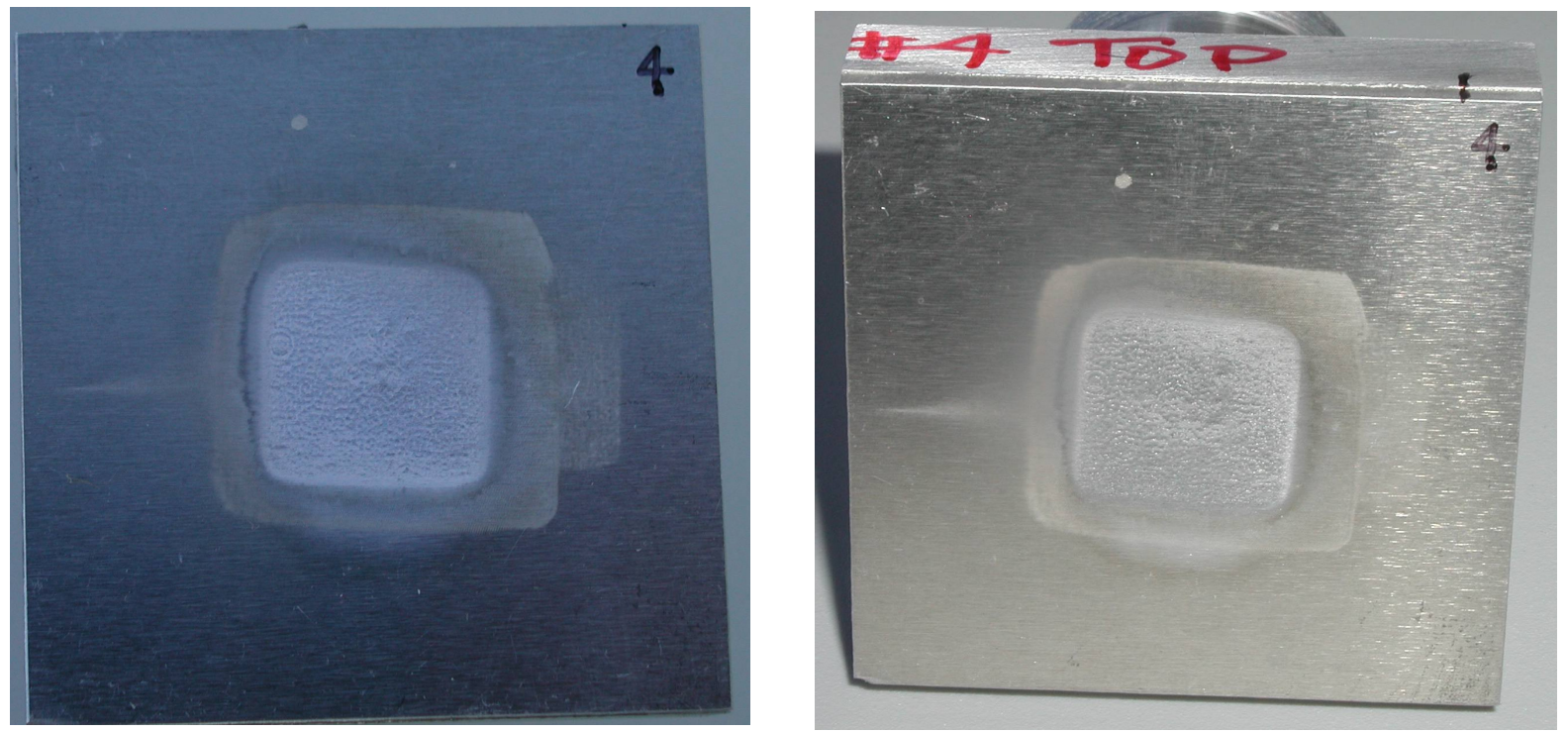

Figure A-1. Photographs of shot 4

Fluence: $411 \mathrm{~J} / \mathrm{cm}^{2}$

Sample: $2 \mathrm{~mm}$ Aluminum
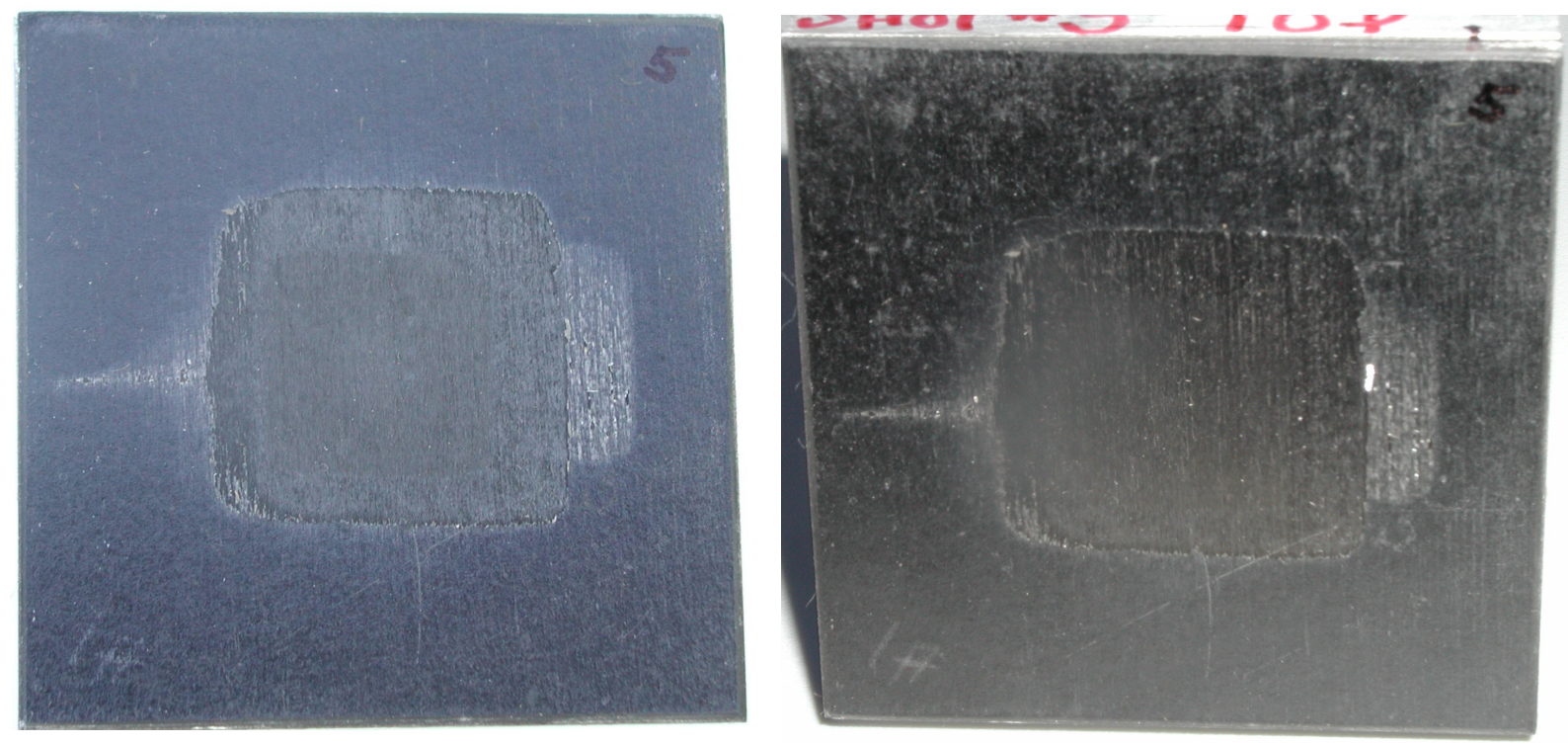

Figure A-2. Photographs of shot 5

Fluence: $411 \mathrm{~J} / \mathrm{cm}^{2}$

Sample: Graphite Epoxy 

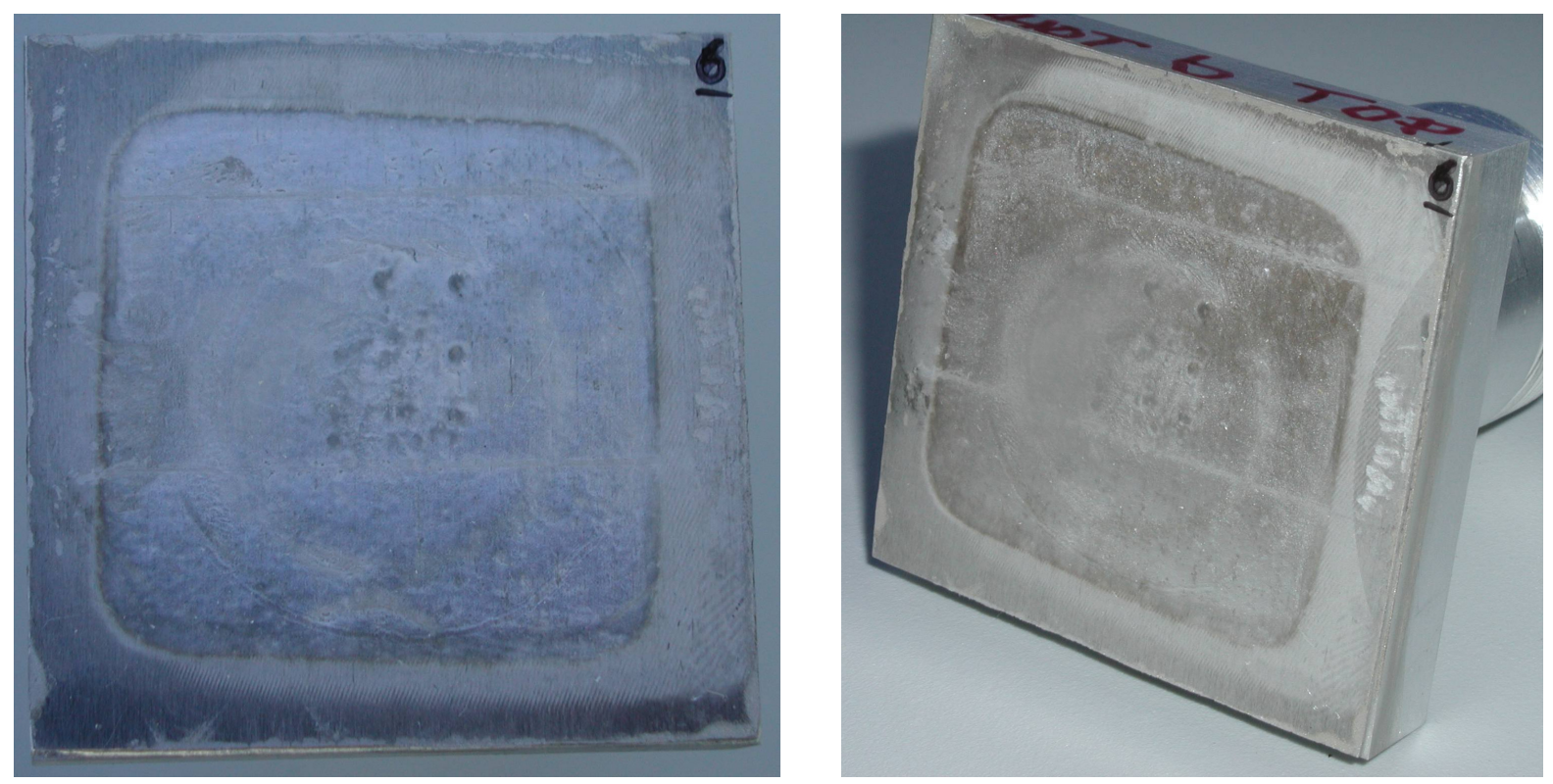

Figure A-3. Photographs of sample tested on shots 2 and 6 Fluence: $75 \mathrm{~J} / \mathrm{cm}^{2}$ Sample: $1 \mathrm{~mm}$ Aluminum
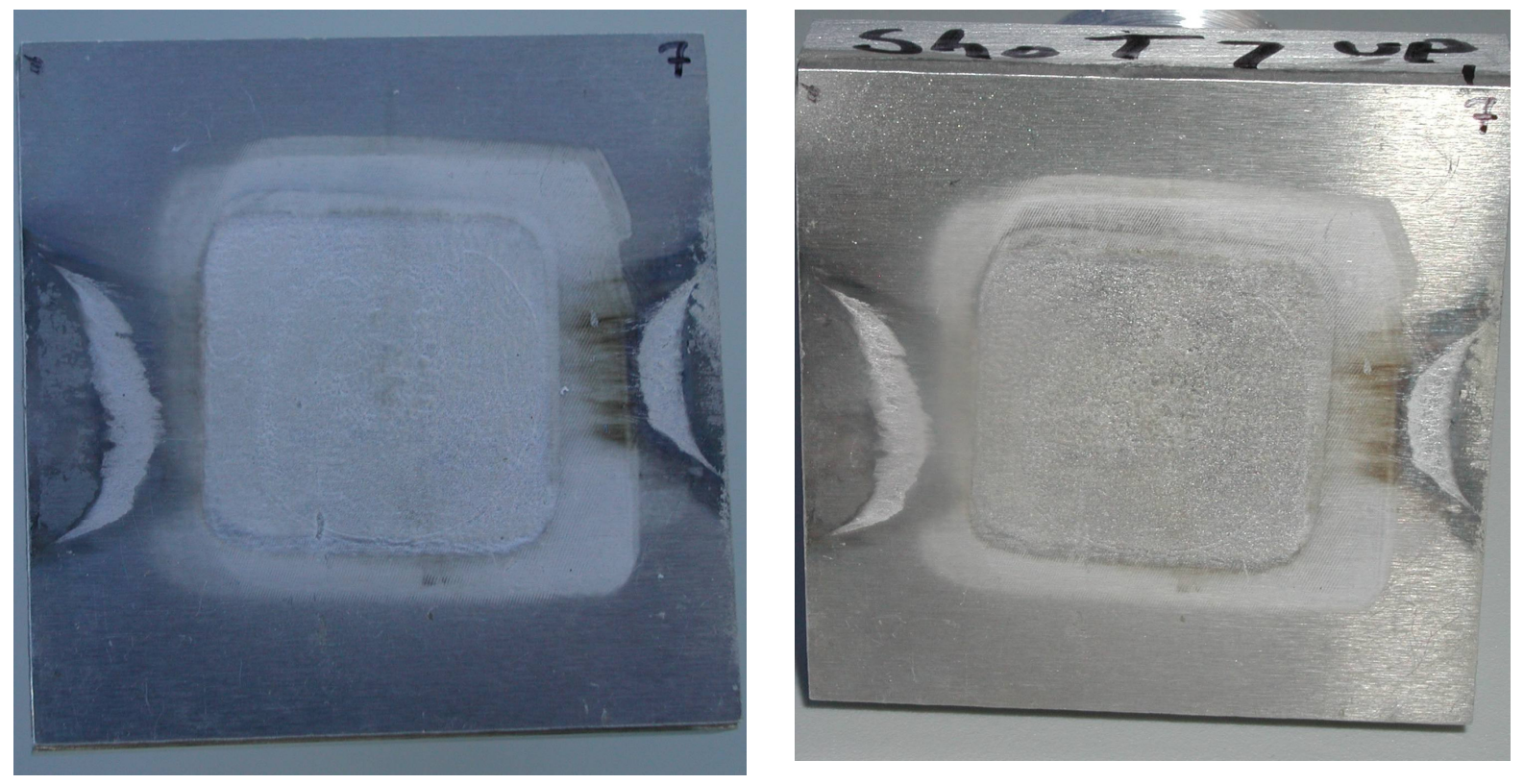

Figure A-4. Photographs of sample tested on shots 1 and 7 Fluence: $175 \mathrm{~J} / \mathrm{cm}^{2}$

Sample: $2.5 \mathrm{~mm}$ Aluminum 

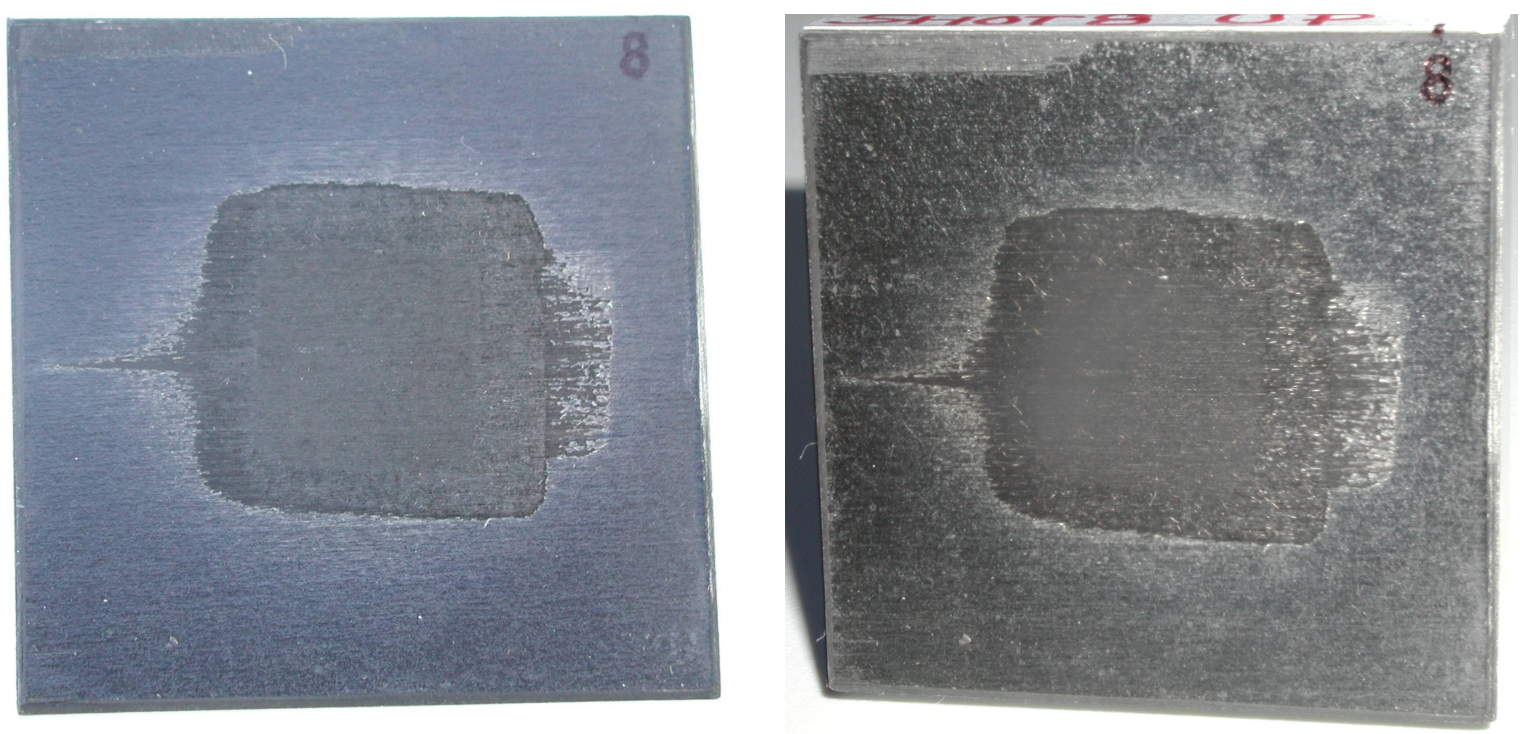

Figure A-5. Photographs of shot 8

Fluence: $411 \mathrm{~J} / \mathrm{cm}^{2}$

Sample: Graphite Epoxy
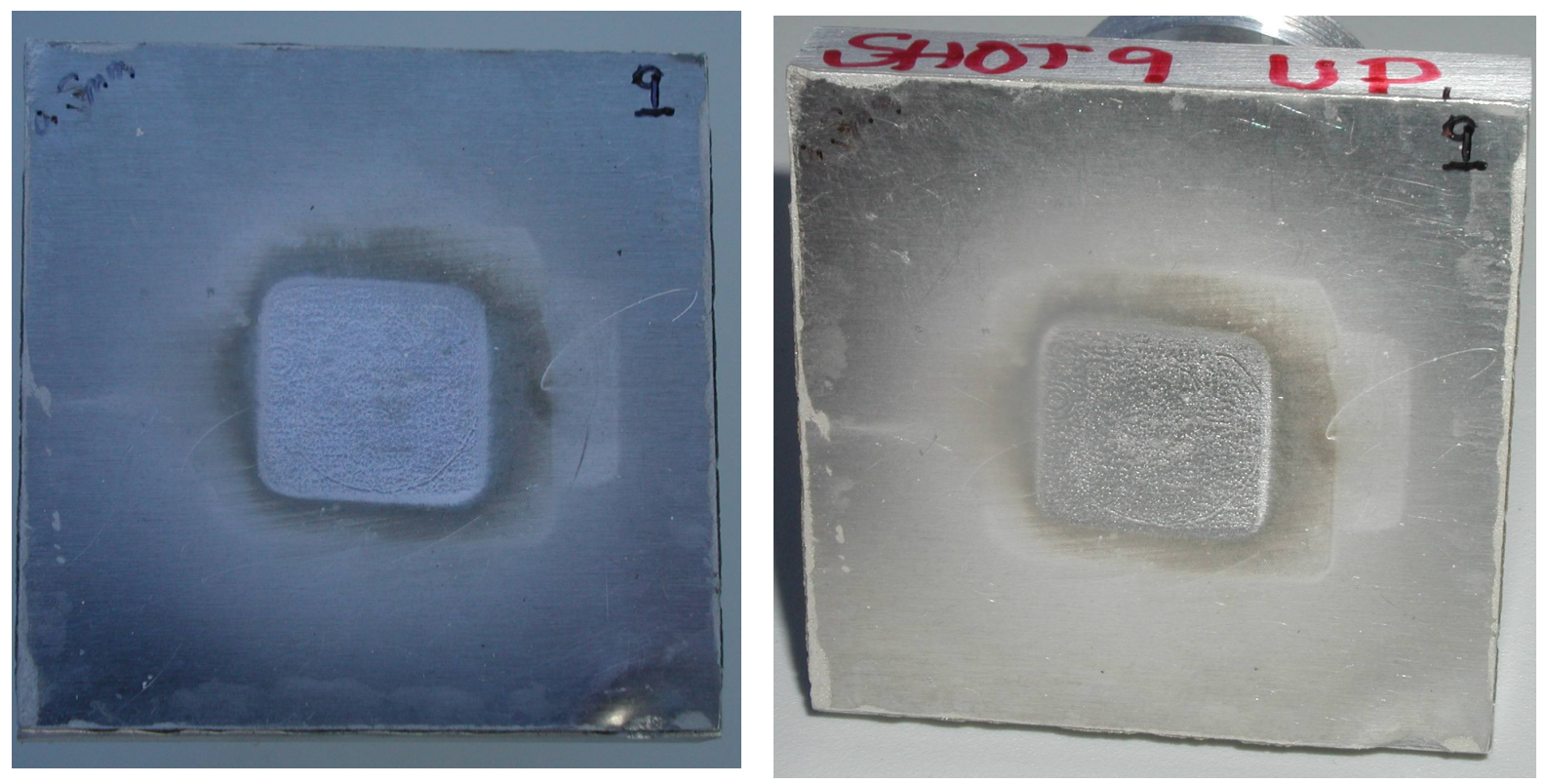

Figure A-6. Photographs of shot 9.

Note lower right corner was bent during posttest handling.

Fluence: $411 \mathrm{~J} / \mathrm{cm}^{2}$

Sample: $0.5 \mathrm{~mm}$ Aluminum 

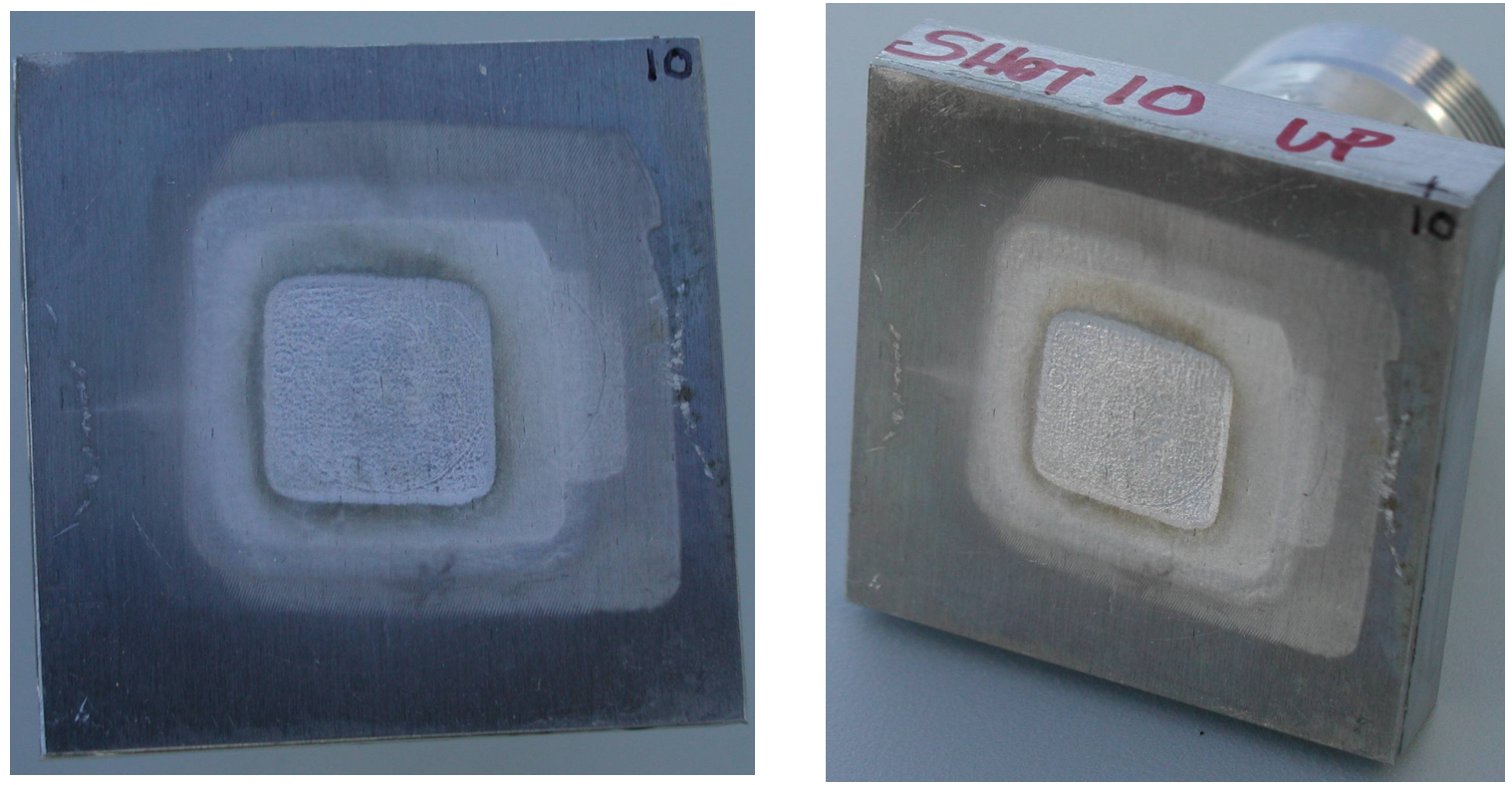

Figure A-7. Photographs of sample tested on Shots 3 and 10

Fluence: 125 and $411 \mathrm{~J} / \mathrm{cm}^{2}$

Sample: $1.5 \mathrm{~mm}$ Aluminum
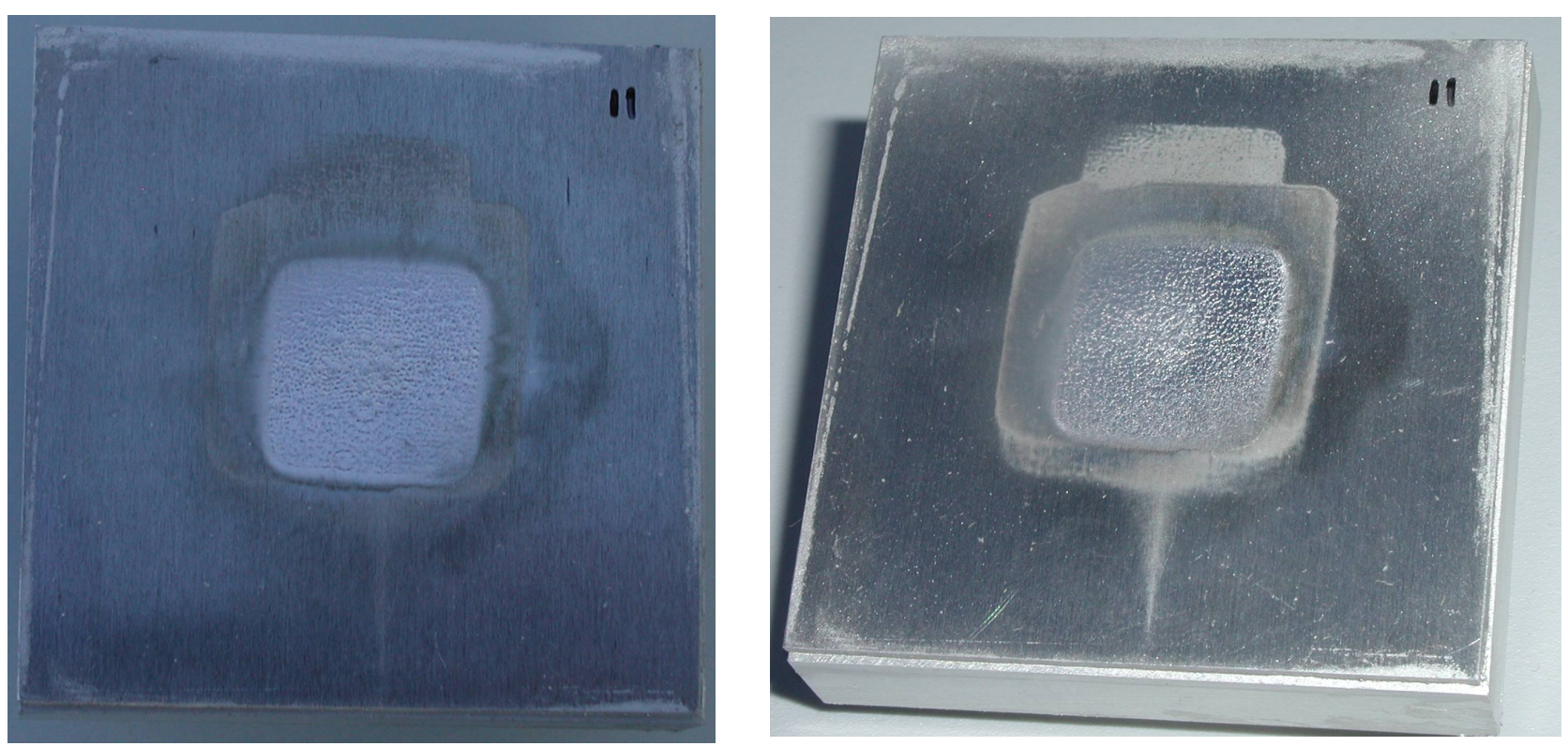

Figure A-8. Photographs of shot 11

Fluence: $411 \mathrm{~J} / \mathrm{cm}^{2}$

Sample: $1.0 \mathrm{~mm}$ Aluminum 

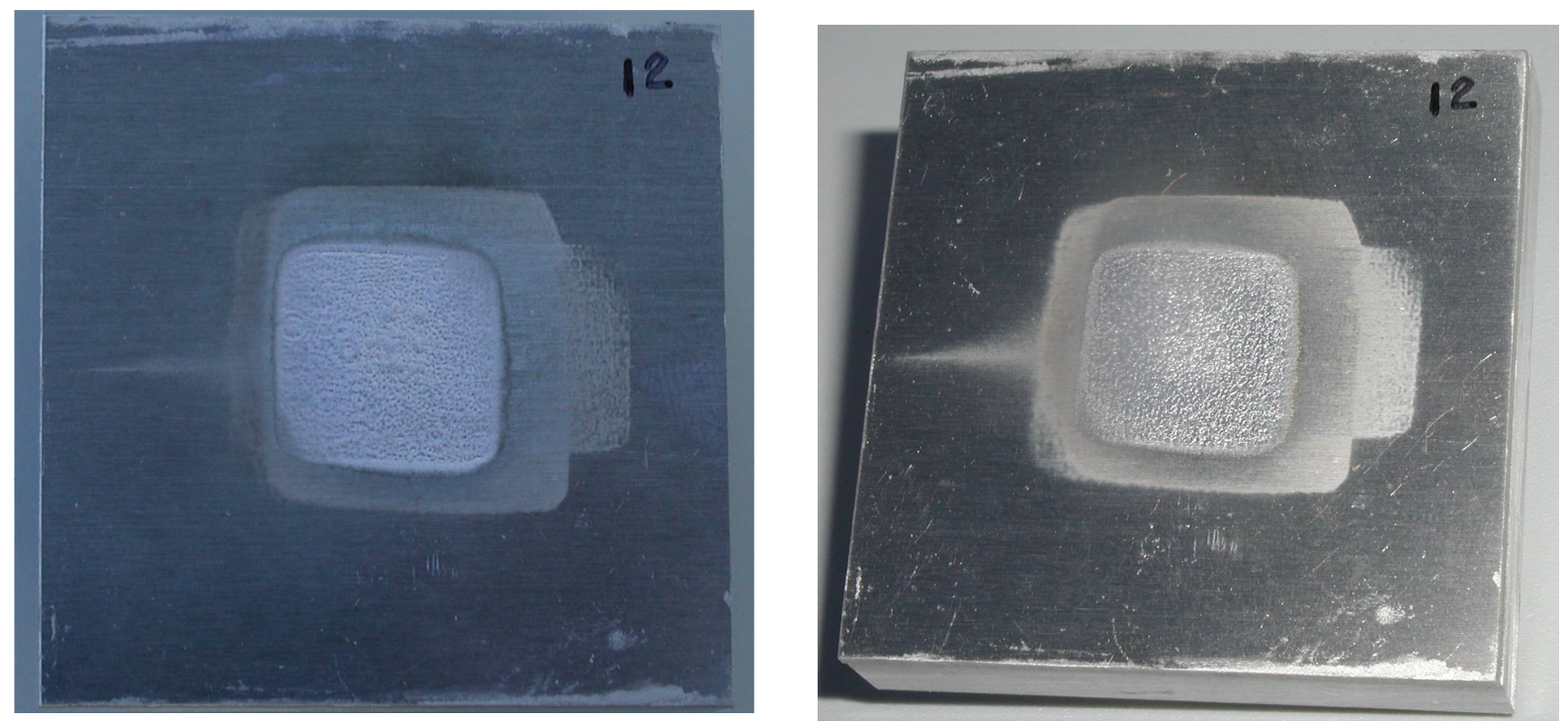

Figure A-9. Photographs of shot 12

Fluence: $411 \mathrm{~J} / \mathrm{cm}^{2}$

Sample: $1.5 \mathrm{~mm}$ Aluminum 


\section{Appendix B: Ablation depth measurements}

The following pages contain surface profile measurements of the ablated sample surface for all shots. A color contour plot of the 3D surface and two 2D plots of the $x-z$ and $y-z$ profiles near the center of the sample are presented for each shot.

The sample ablated surfaces were measured with a Talysurf CLI 2000 3D Surface Profiling System with a CLA Confocal Gauge 300BE non-contact gauge head. (Reference: Manufacturing Science and Technology Center at the Sandia National Laboratory.) The specifications are as follows:

- 300 um range

- $\quad$ step height repeatability $=2 \mathrm{~nm}$

- noise level $=5 \mathrm{~nm}$

- $\quad$ spot diameter $=8$ um

- $\quad$ vertical resolution $=10 \mathrm{~nm}$

Note: On Shots 11 and 12, the yellow portions of the 3D plots are where the vertical range of the profilometer head was exceeded while scanning. 

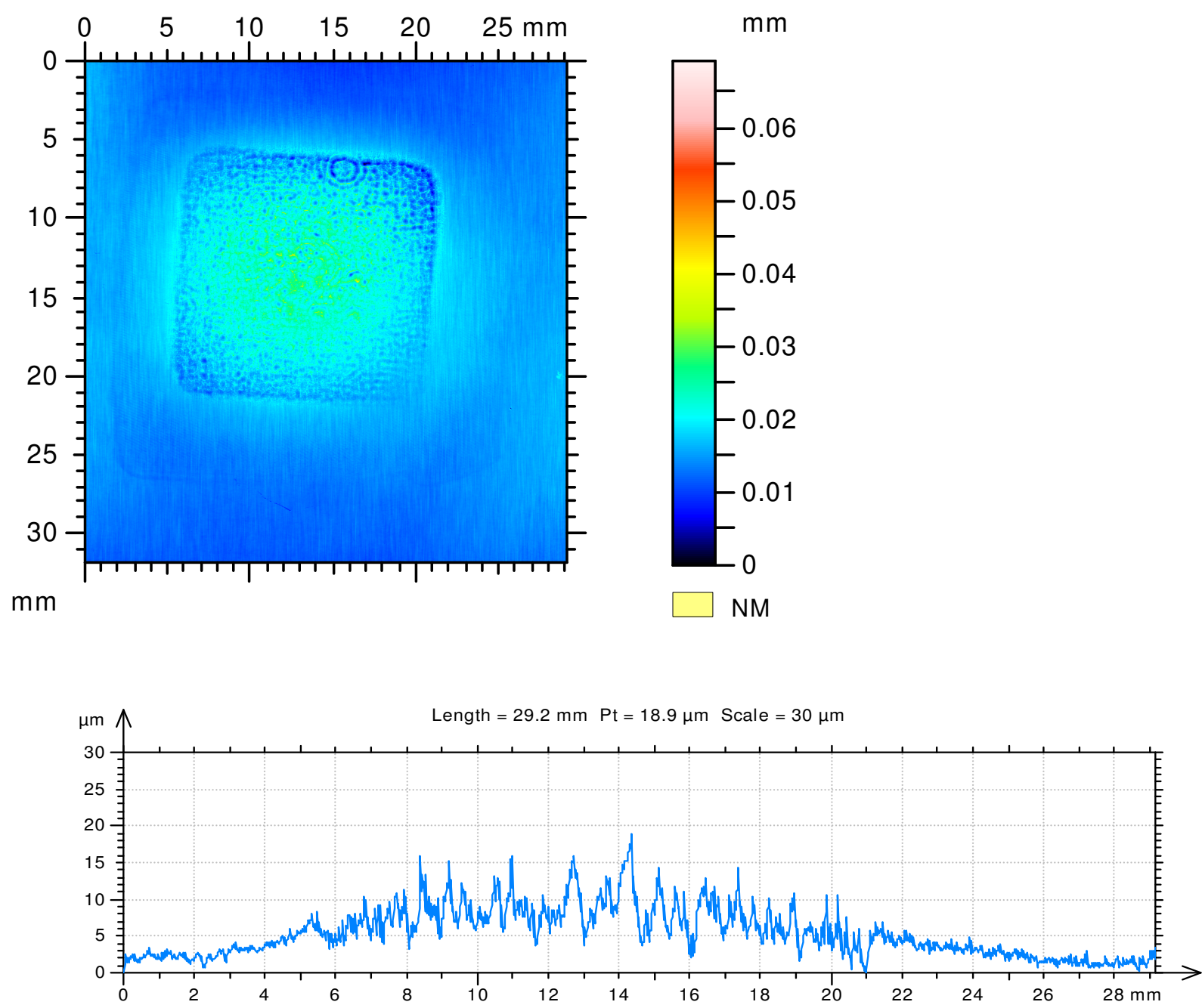

Extracted Profile (west to east) of Leveled Data at $Y=13.7 \mathrm{~mm}$

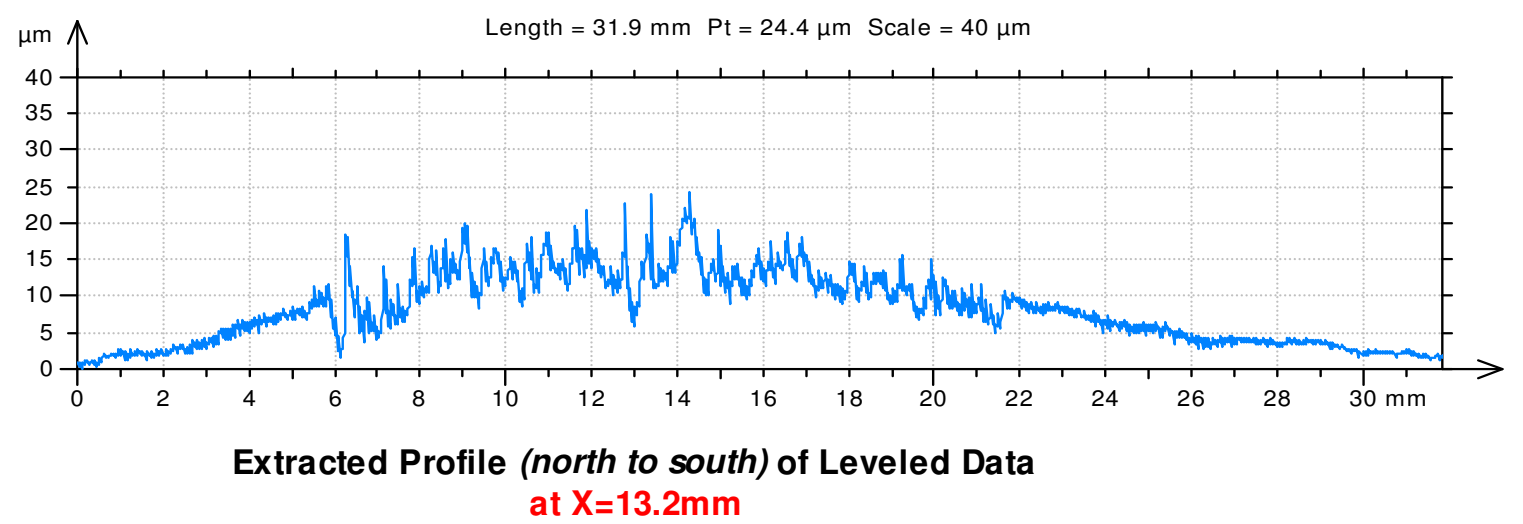

Figure B-1. Shot 4 Surface 3D and 2D profiles. 

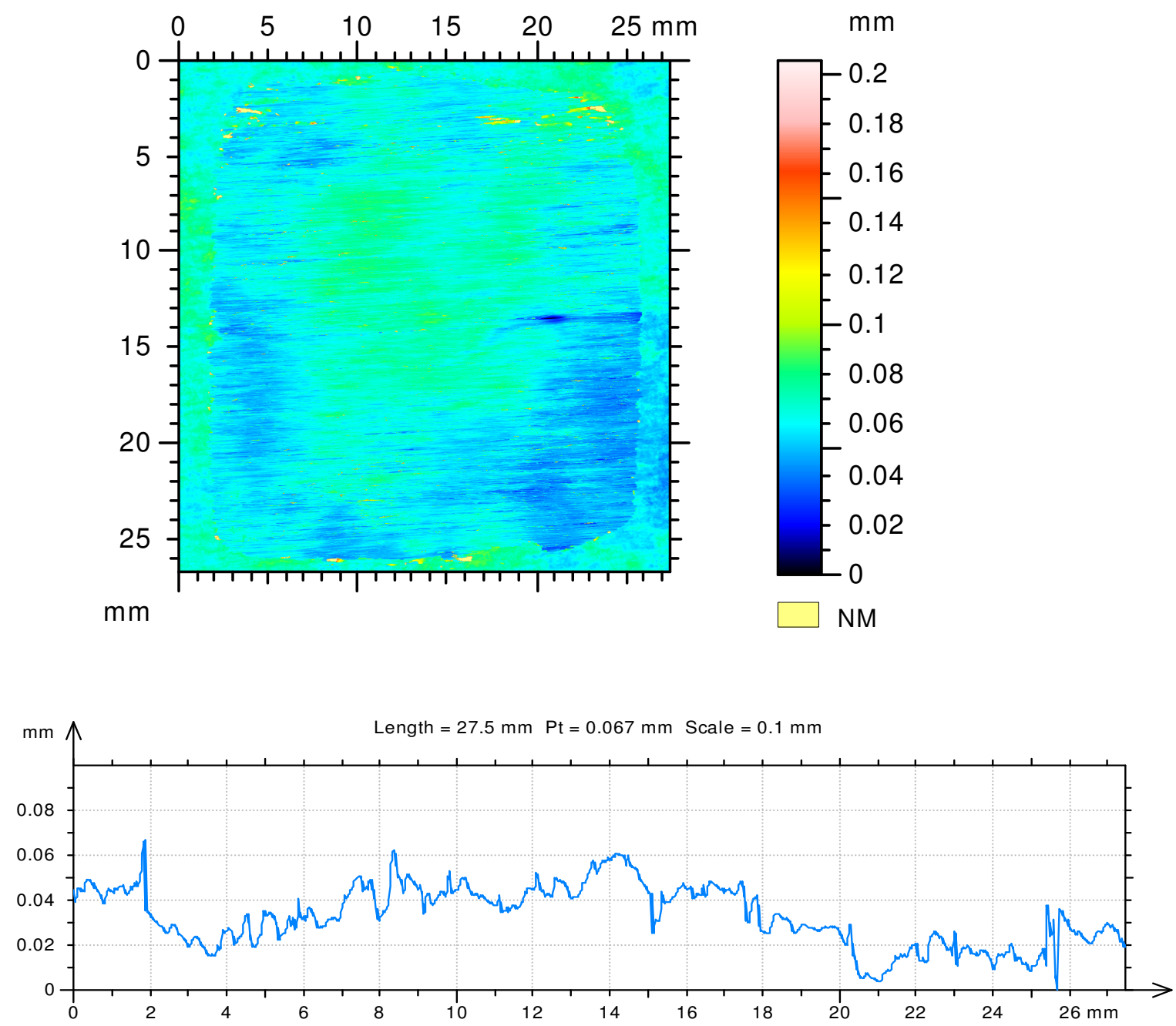

Extracted Profile (west to east) of Leveled Data at $Y=13.7 \mathrm{~mm}$

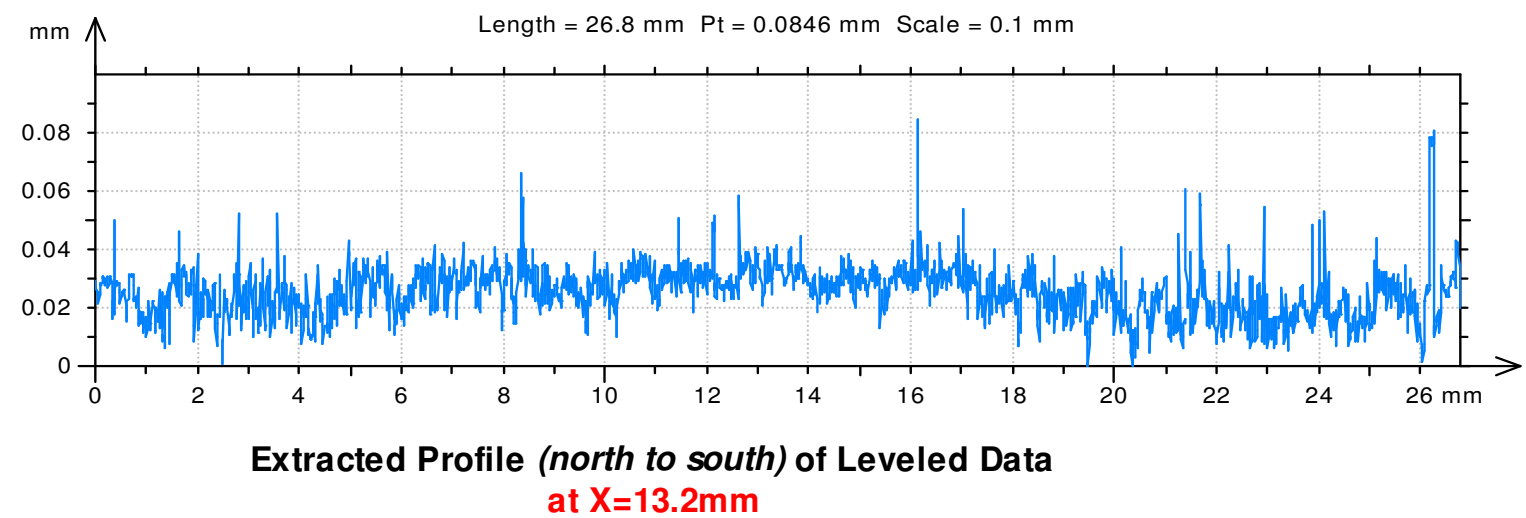

Figure B-2. Shot 5 Surface 3D and 2D profiles. 

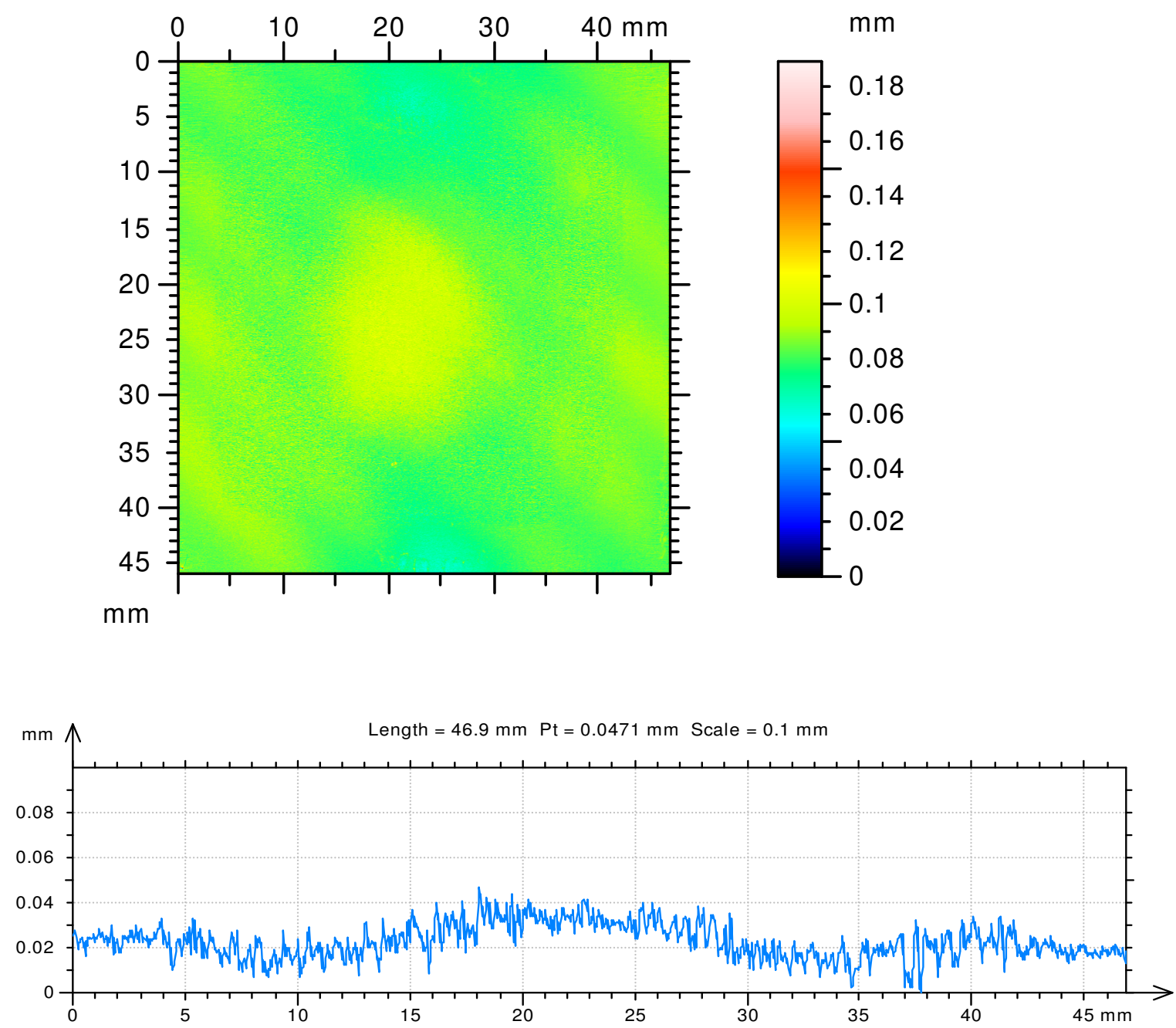

Extracted Profile (west to east) of Leveled Data at $\mathrm{Y}=23.0 \mathrm{~mm}$

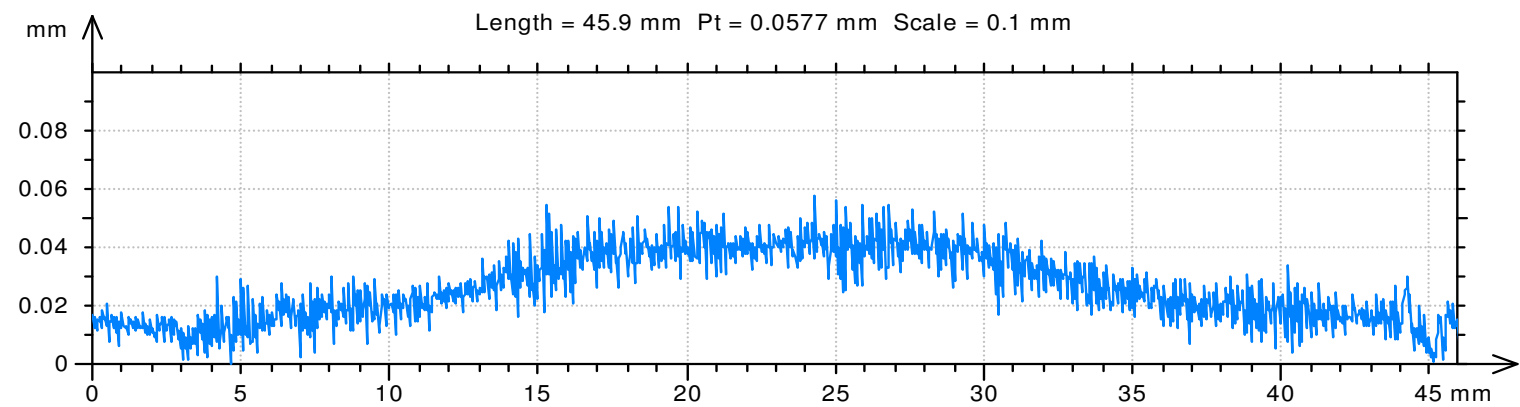

Extracted Profile (north to south) of Leveled Data at $X=21.5 \mathrm{~mm}$

Figure B-3. Shot 6 Surface 3D and 2D profiles. 

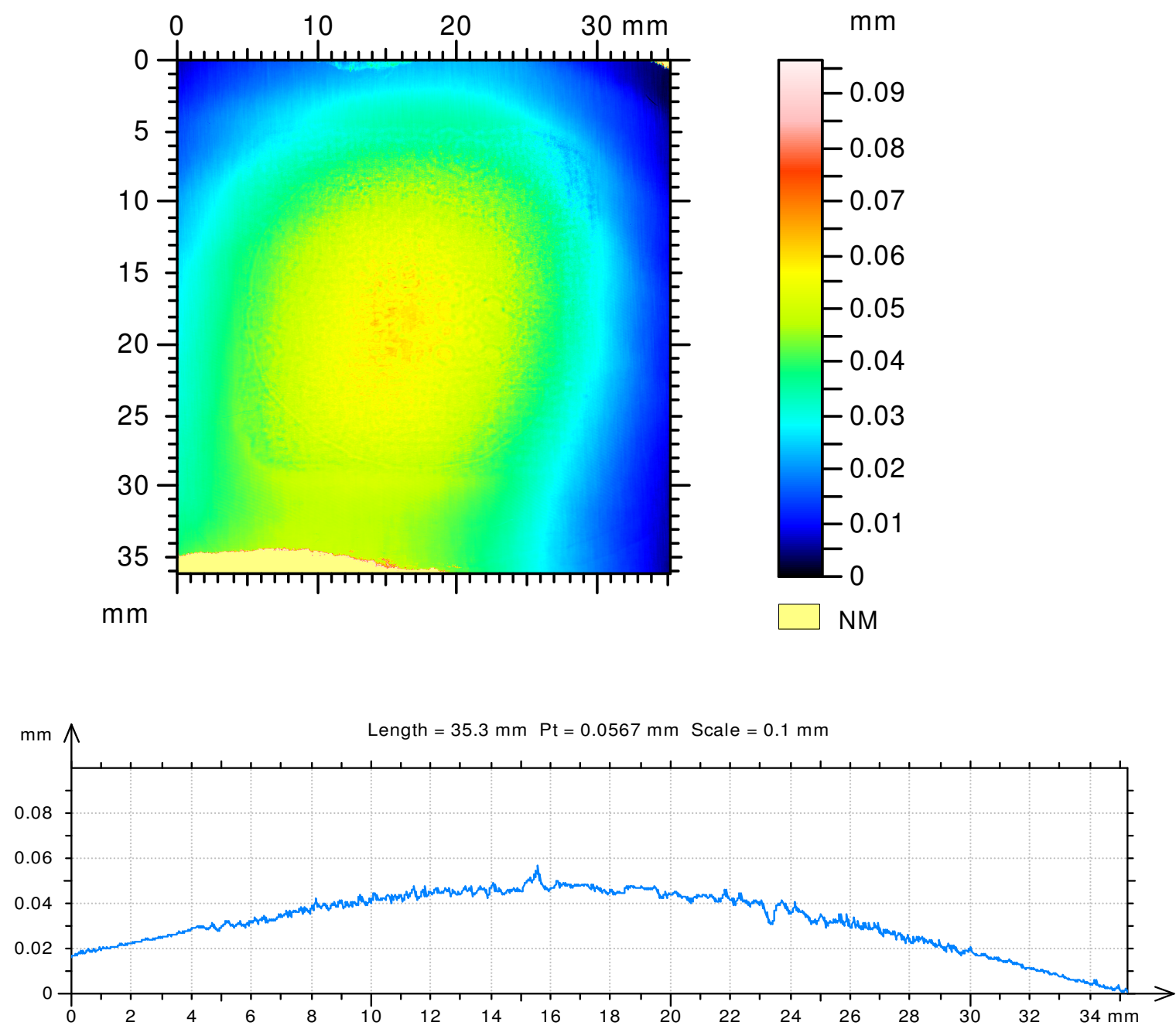

Extracted Profile (west to east) of Leveled Data at $Y=17.5 \mathrm{~mm}$

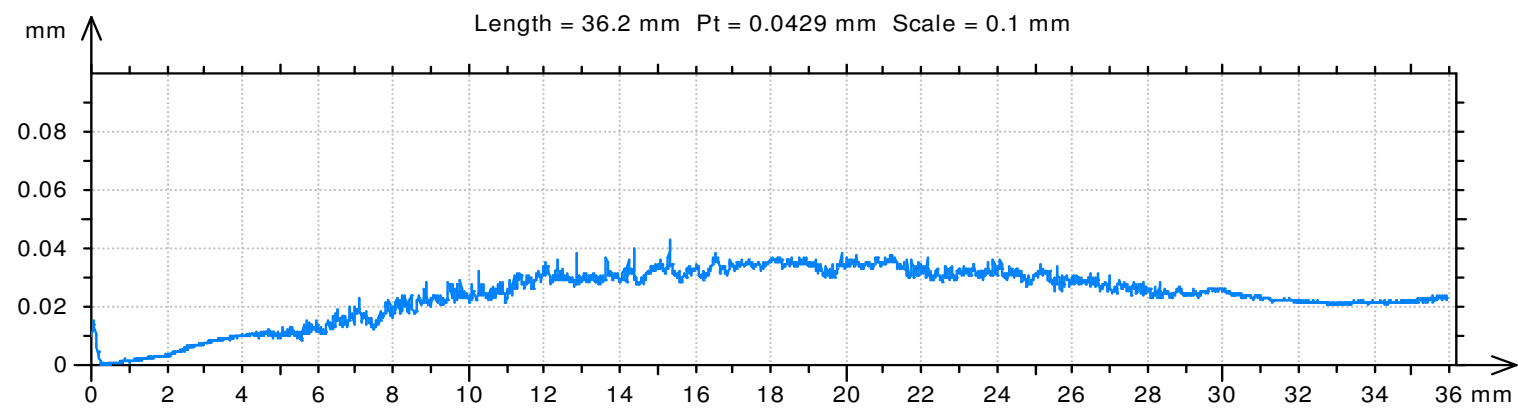

Extracted Profile (north to south) of Leveled Data at $X=16.6 \mathrm{~mm}$

Figure B-4. Shot 7 Surface 3D and 2D profiles. 

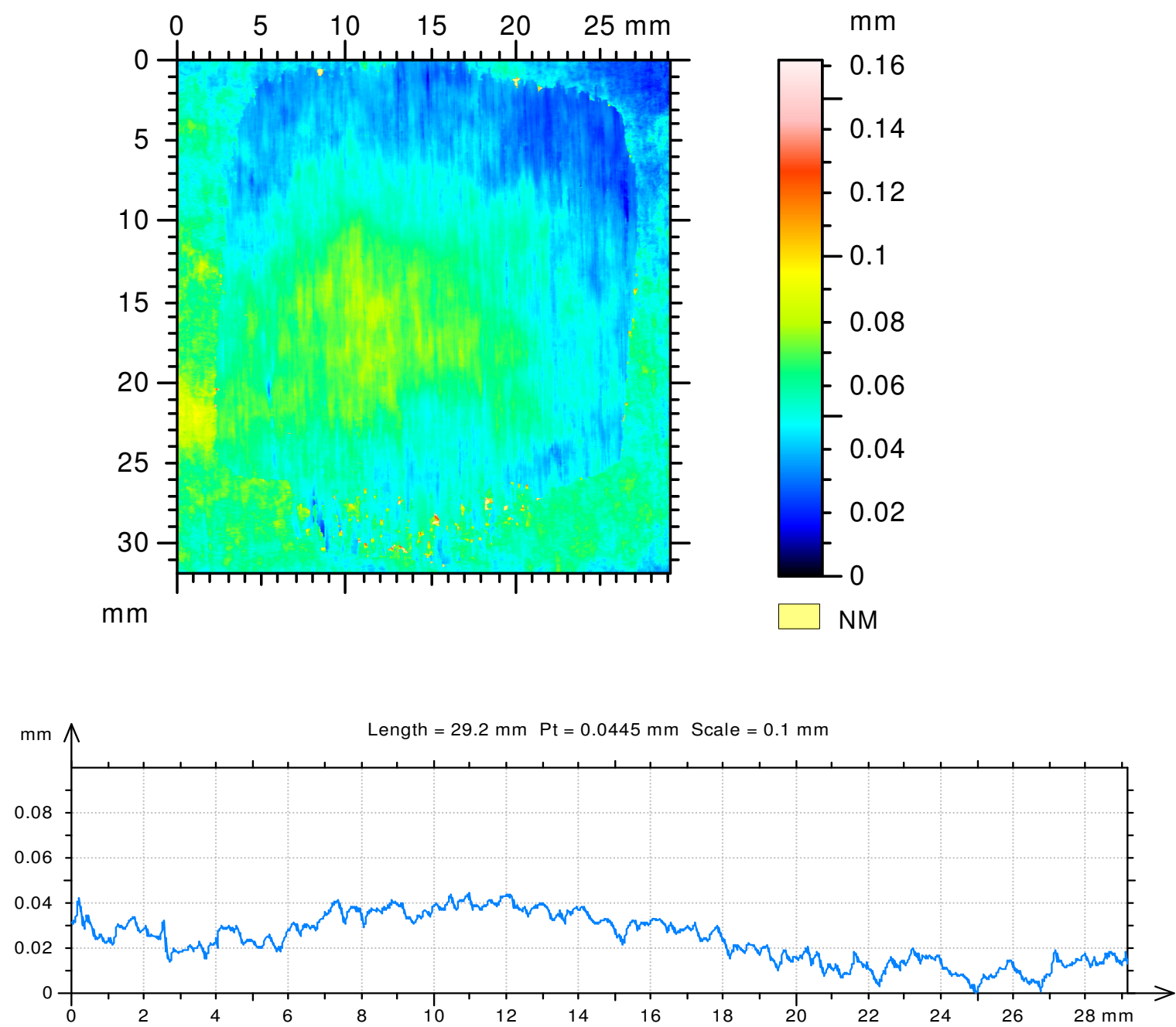

Extracted Profile (west to east) of Leveled Data at $Y=14.7 \mathrm{~mm}$

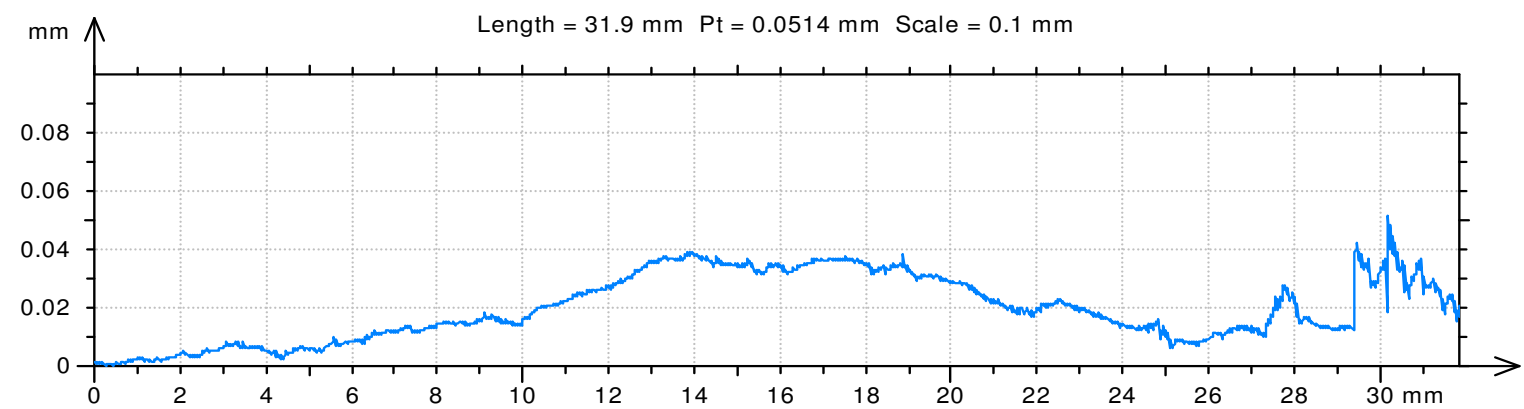

Extracted Profile (north to south) of Leveled Data at $\mathrm{X}=13.8 \mathrm{~mm}$

Figure B-5. Shot 8 Surface 3D and 2D profiles. 

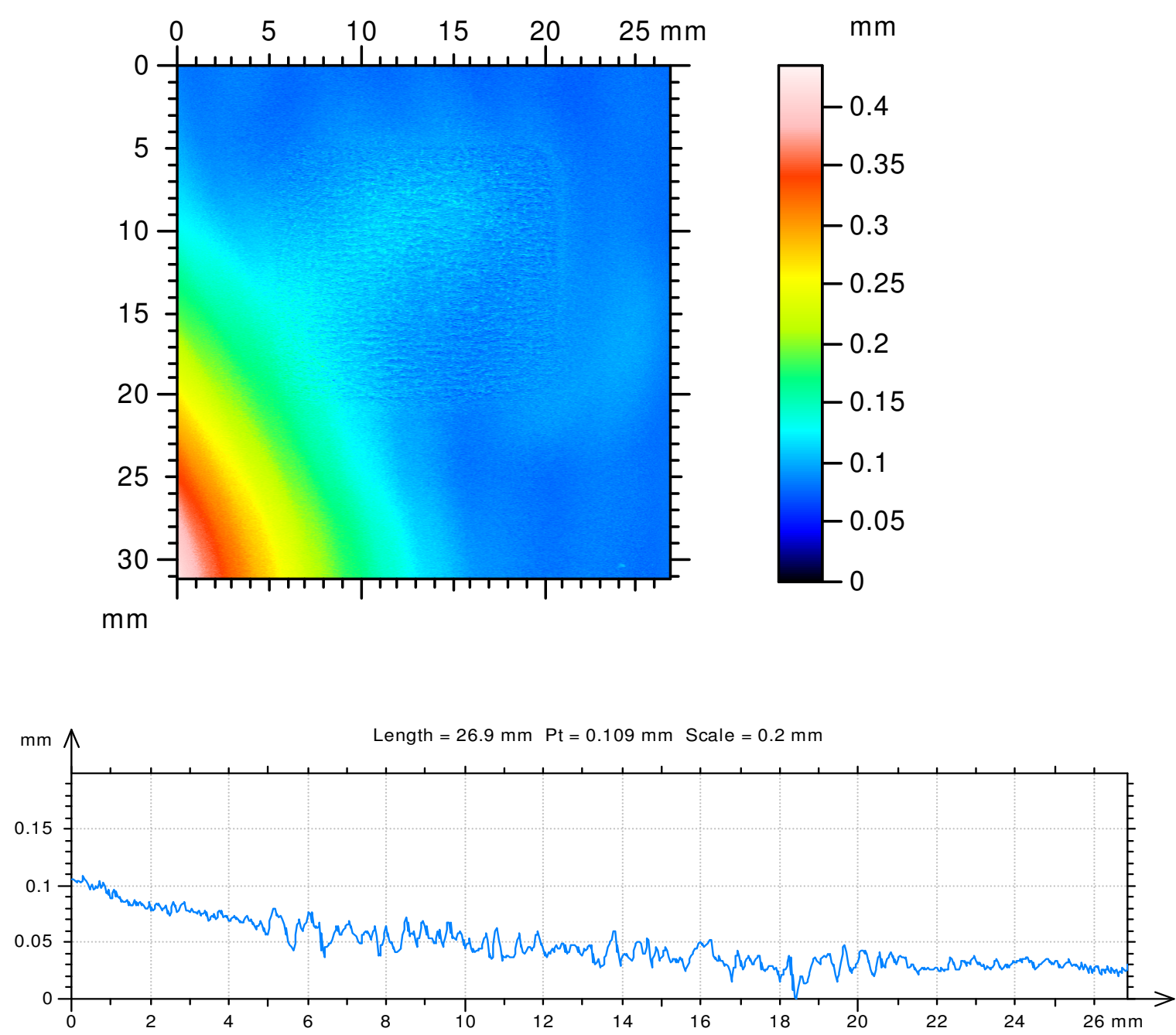

Extracted Profile (west to east) of Leveled Data at $Y=13.0 \mathrm{~mm}$

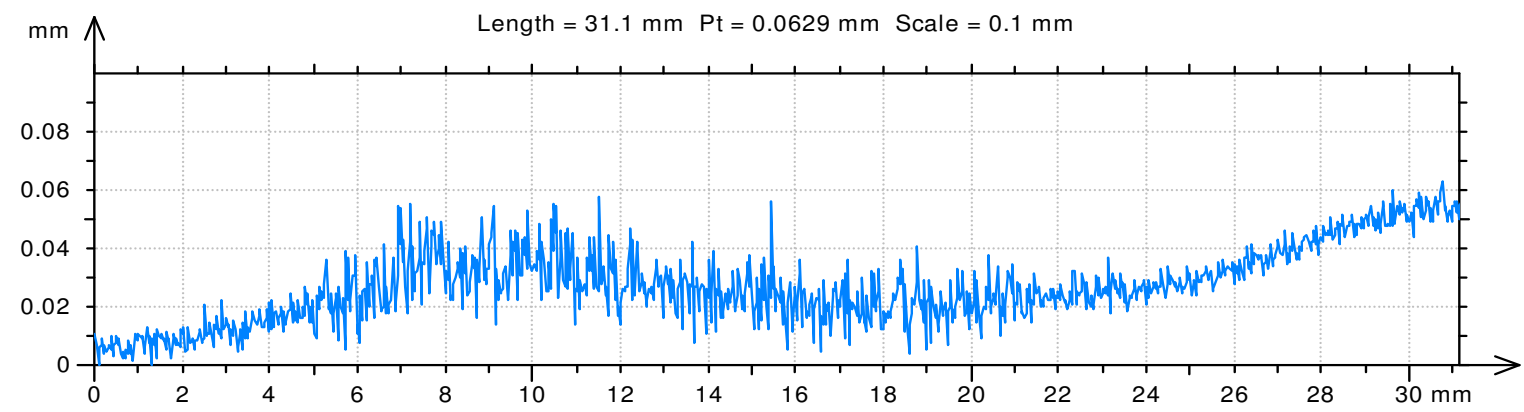

Extracted Profile (north to south) of Leveled Data at $X=12.6 \mathrm{~mm}$

Figure B-6. Shot 9 Surface 3D and 2D profiles. 

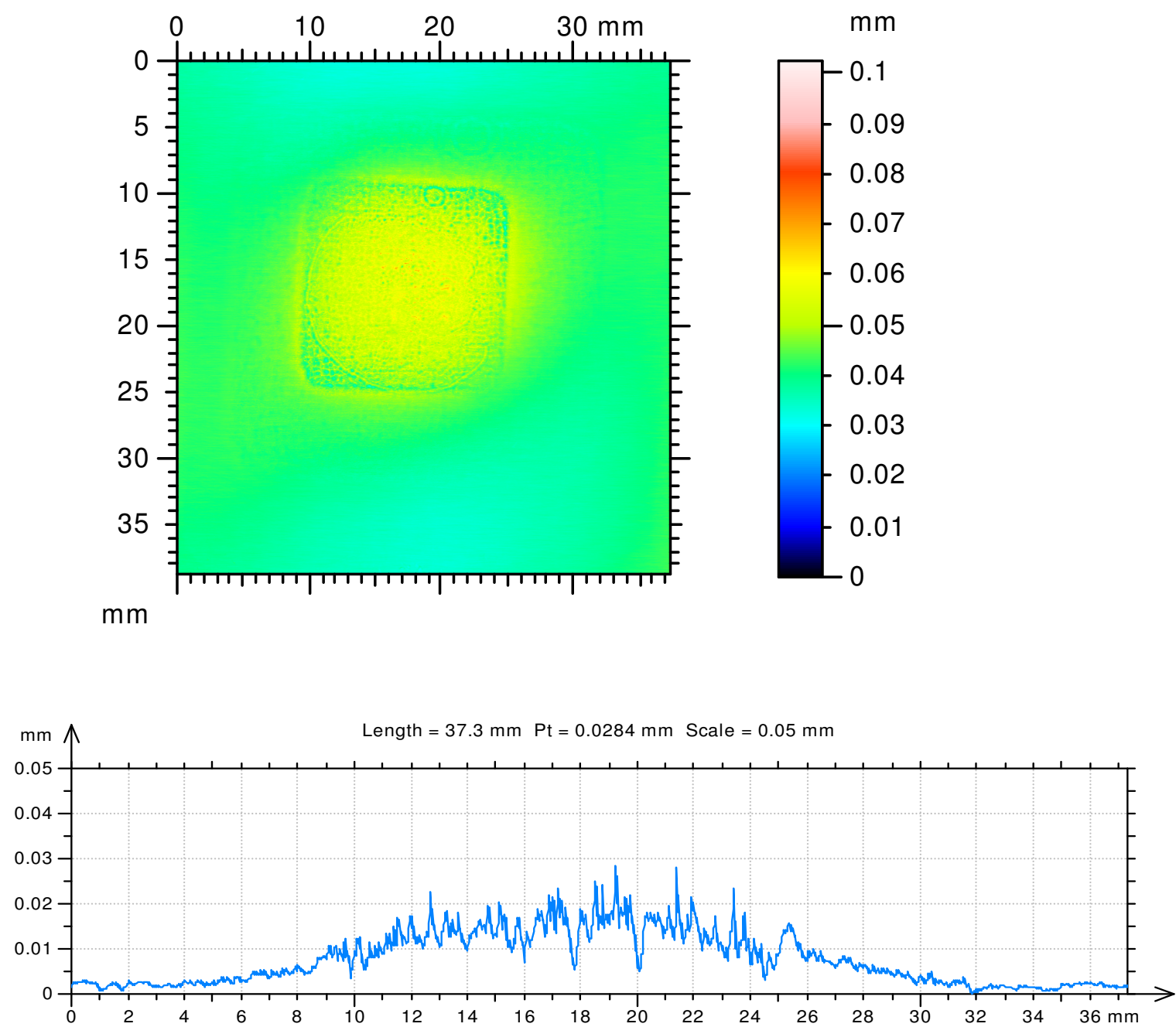

Extracted Profile (west to east) of Leveled Data at $Y=16.8 \mathrm{~mm}$

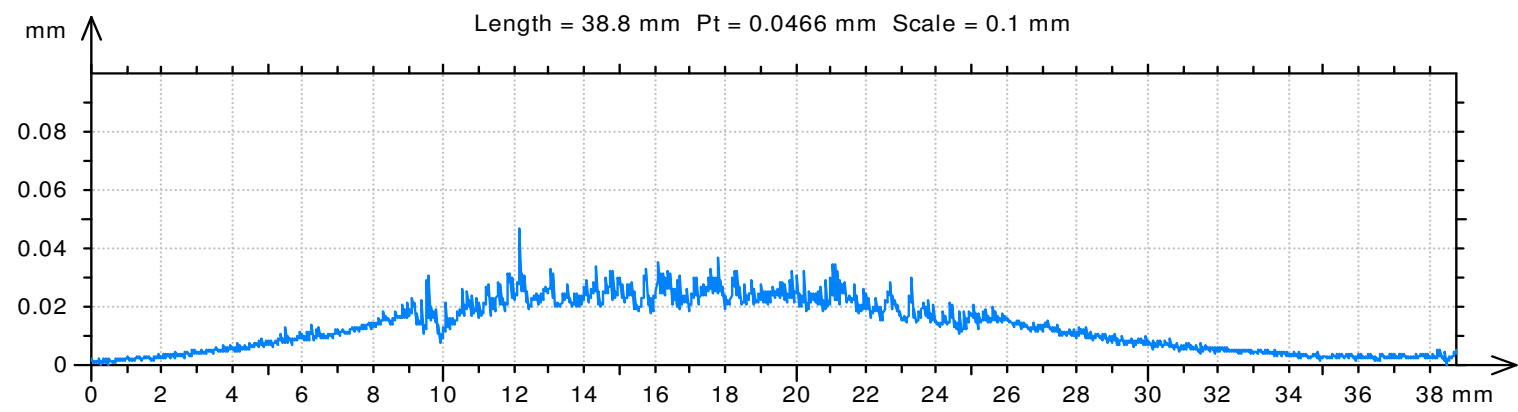

Extracted Profile (north to south) of Leveled Data at $X=17.1 \mathrm{~mm}$

Figure B-7. Shot 10 Surface 3D and 2D profiles. 

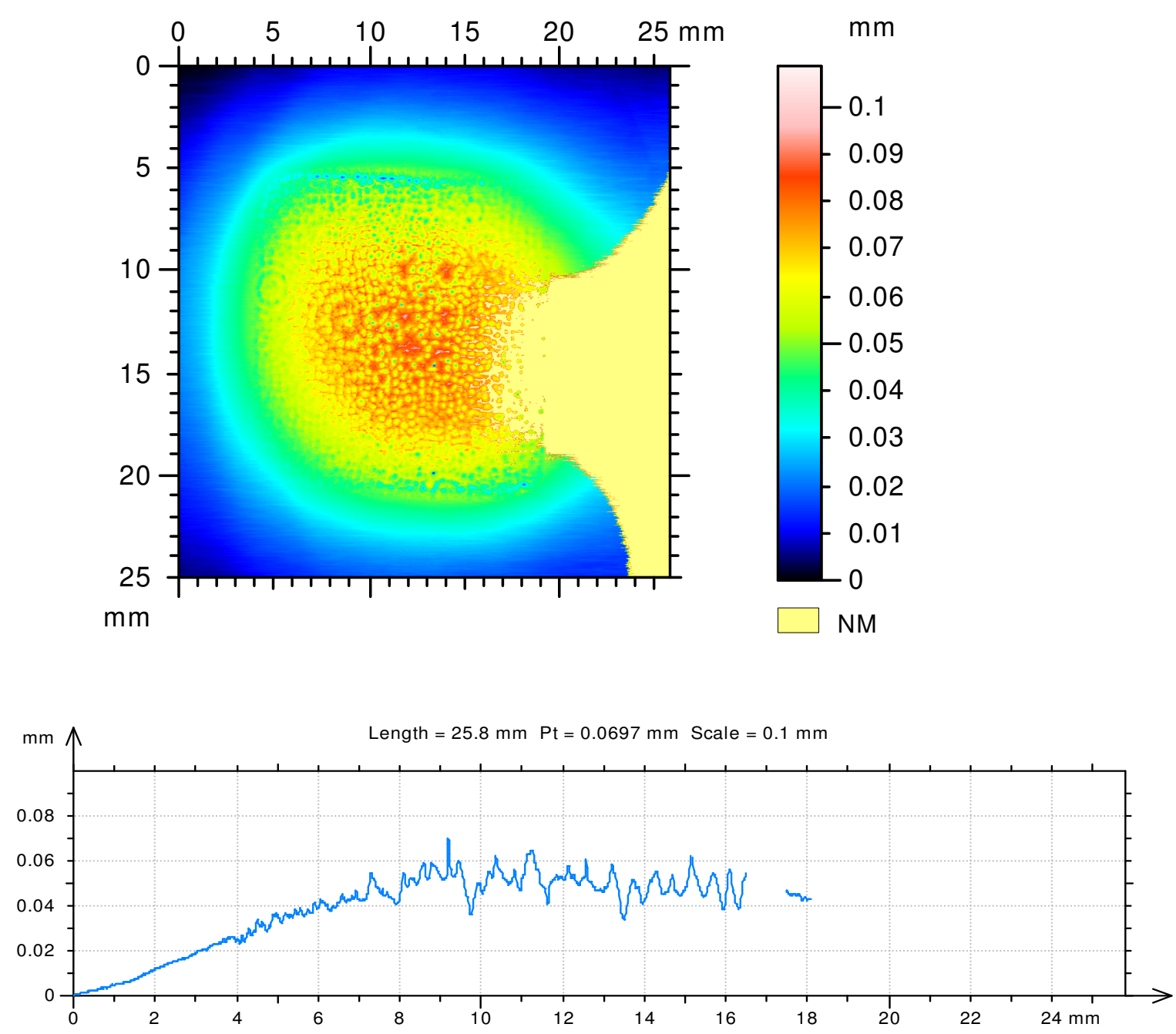

Extracted Profile (west to east) of Leveled Data at $\mathrm{Y}=13.0 \mathrm{~mm}$

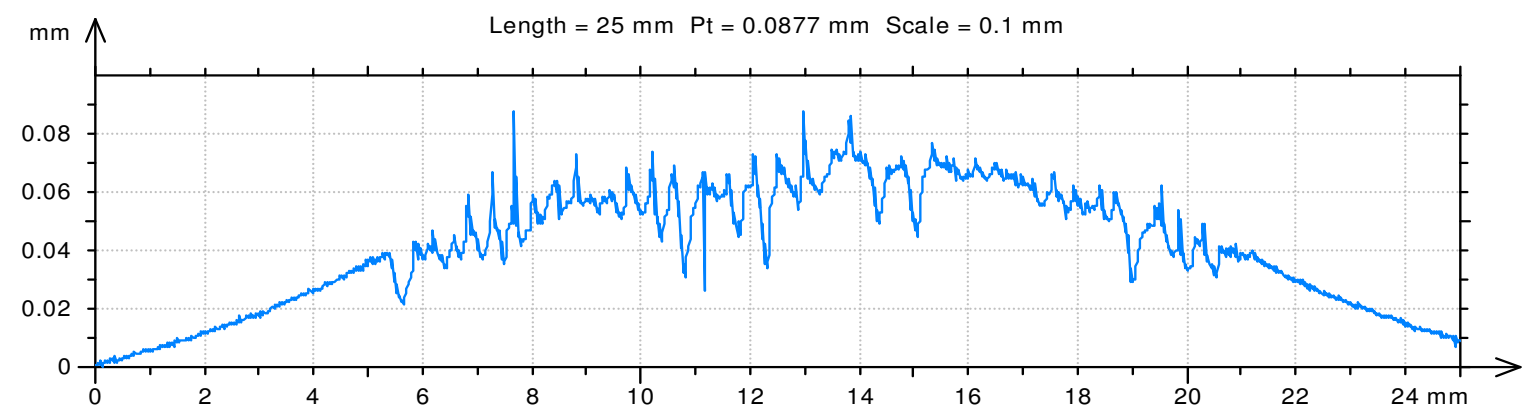

Extracted Profile (north to south) of Leveled Data at $X=12.5 \mathrm{~mm}$

Figure B-8. Shot 11 Surface 3D and 2D profiles. 

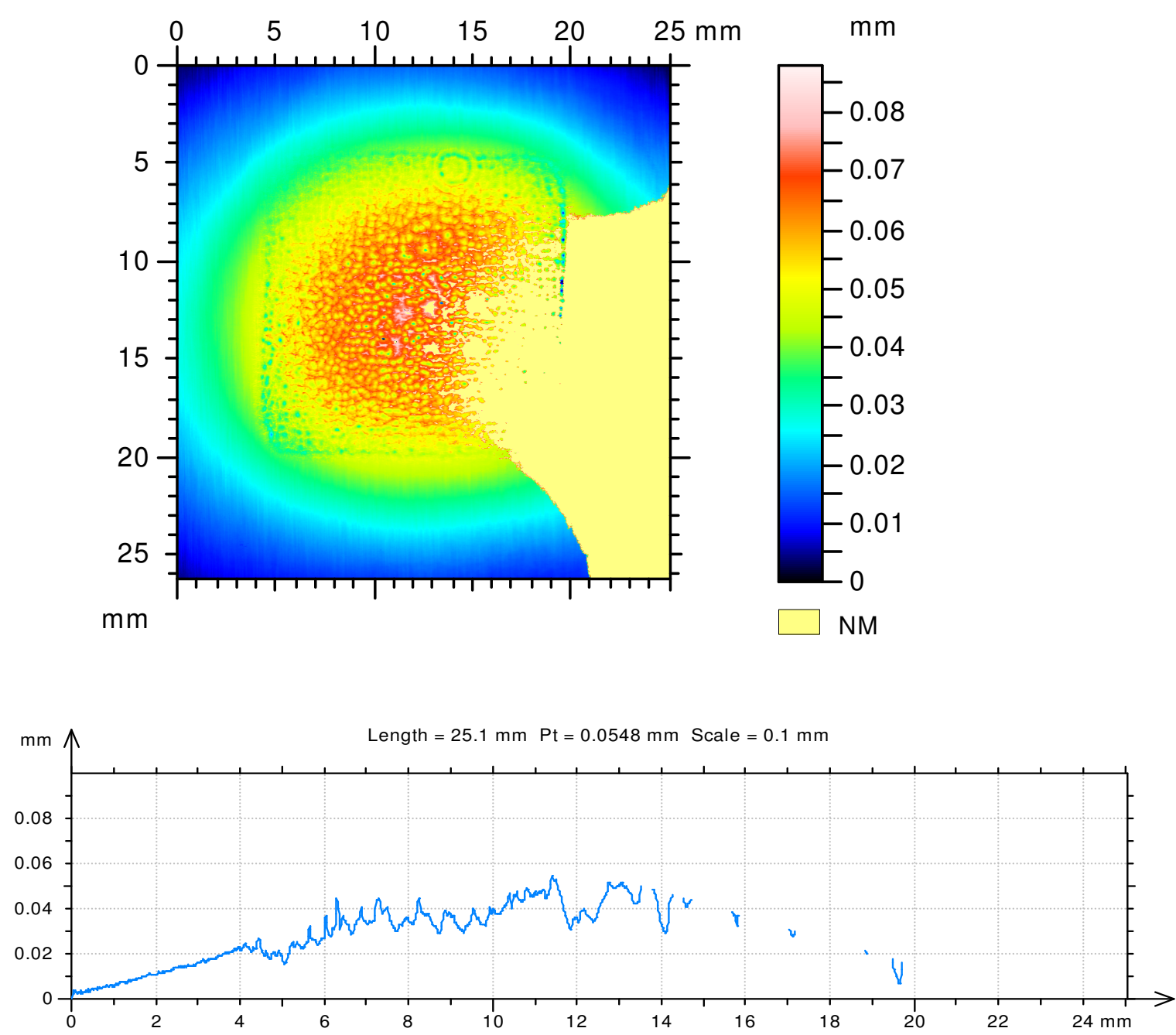

Extracted Profile (west to east) of Leveled Data at $\mathrm{Y}=12.0 \mathrm{~mm}$

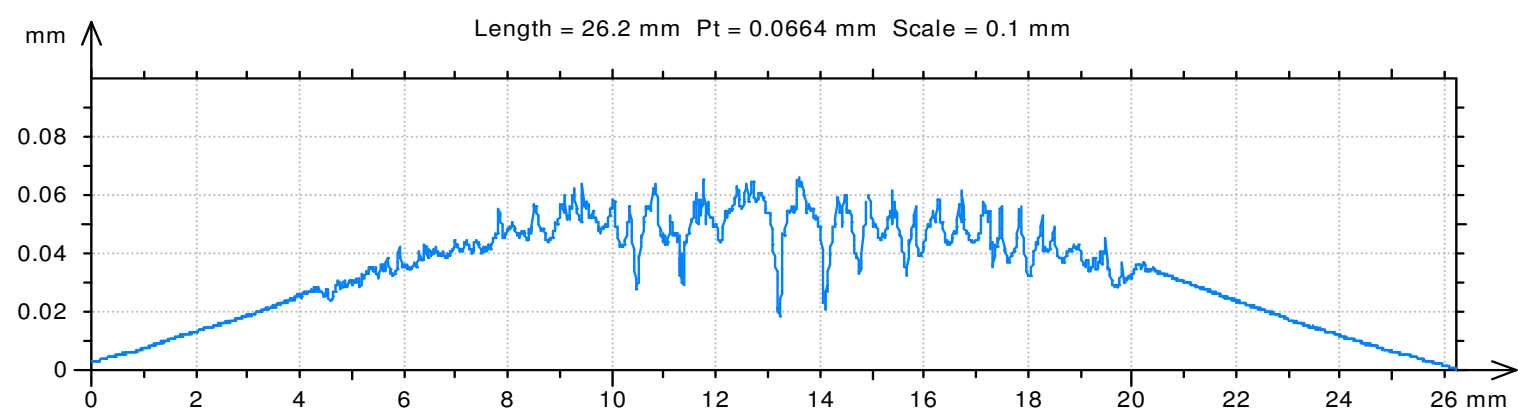

Extracted Profile (north to south) of Leveled Data at $X=12.0 \mathrm{~mm}$

Figure B-9. Shot 12 Surface 3D and 2D profiles. 


\section{Distribution List}

\section{LLNL}

Kevin Fornier

Mike Tobin

Ktech Corp

File

Eric Smith

Bill Bonahoom

Frank Dean

Don Sullivan 